\title{
Have structural changes eliminated the out-of-sample ability of financial variables to forecast real activity after the mid-1980s? Evidence from the Canadian economy.
}

\author{
Akhter Faroque \\ Department of Economics \\ Laurentian University \\ Sudbury, Ontario \\ Canada \\ afaroque@laurentian.ca
}

\author{
William Veloce \\ Department of Economics \\ Brock University \\ St. Catharines, Ontario \\ Canada \\ wmveloce@brocku.ca
}

\author{
Jean-Francois Lamarche \\ Department of Economics \\ Brock University \\ St. Catharines, Ontario \\ Canada \\ jfl@brocku.ca
}

\begin{abstract}
The paper evaluates how consistently reliable the information content of individual financial variables is for Canada's future output growth. We estimate the timing of structural changes in linear growth models and check robustness to specification changes, multiple breaks, and business cycle asymmetry. Our simulated out-of-sample forecast evaluation strategy, using the MSE-F and the ENC-NEW tests, shows that the leading information content of most financial variables for Canada's future GDP growth has deteriorated substantially after 1984:4, but the 1-3 year term spread exhibits a consistently reliable predictive ability at the 1 and 2 quarter horizons and has significant forecasting ability at the 8 quarter horizon. Also, the real M1 money growth has regained its ability to forecast output growth since 1991:1. (JEL C52, C53, E44)
\end{abstract}




\section{Introduction}

In their landmark multi-country study, Stock and Watson (2003) have shown that the out-of-sample predictive ability of many individual financial variables for real GDP growth may have broken down in several countries, including Canada, after the mid-1980s, due to structural changes within countries. In a follow-up study focusing on the US, Rapach and Weber (2004) demonstrate that many of these same variables exhibit a significant ability to forecast U.S. GDP growth after the mid-1980s, provided the forecasts are evaluated using the more powerful encompassing tests of Clark and McCracken $(2001,2005)$ instead of the traditional minimum mean square forecast error (MSFE) tests used by Stock and Watson (2003). The Rapach-Weber finding implies that structural changes may have weakened, but not eliminated, the information content of individual financial variables. Their finding is also consistent with the evidence from a related strand of the literature that shows that combinations of financial variables (weighted averages, composite financial indexes or factor models) are able to produce reliable forecast of real activity after the mid-1980s ${ }^{1}$ (Goodhart and Hofmann, 2001; Bernanke and Boivin, 2003).

The primary purpose of this paper is to evaluate the reliability of the out-of-sample information content of individual financial indicators of Canada's real GDP growth at different forecast horizons. The study is motivated by three considerations. First, we are interested in determining whether the Rapach-Weber finding for the US economy also generalizes to the Canadian economy. Second, an analysis of Canadian data is expected to yield new findings. Financial variables, by virtue of their forward-looking nature, are especially informative about the linkages between the real and the financial sides of an economy ${ }^{2}$. But the strength and the stability of these linkages may differ between countries due to differences in the nature and timing of

\footnotetext{
${ }^{1}$ Cross (2010) notes that diffusion indexes can provide useful additional information about business cycle dynamics. For example, diffusion indexes tend to be highly correlated to GDP growth, indicating that periods of expansion and contraction occur because the impulse to grow or contract is widely dispersed across many industries, not because a few industries are posting exceptional growth or decline.

${ }^{2}$ Bernanke (2004) notes that central bankers naturally turn to asset prices for this advance information, since asset markets are forward-looking, data on assets prices are available on a timely and continuous basis and financial data are not usually revised.
} 
changes in financial and banking regulations, policy regimes, and technological changes between countries. A case in point is that, in spite a high degree of financial and goods market integration between them, the impact of the credit market turmoil that started in late 2007 on the real side of the Canadian economy has been 'mild' relative to its impact on the US economy (Ratkovski and Huang, 2009). A final motivation for this paper is that recent methodological advances show that the interpretation of neither the traditional minimum MSFE tests nor the newer encompassing tests for comparing nested model forecasts is the same in the presence and the absence of forecast bias (Rogoff and Stavrakeva, 2008). This paper applies these tests and also accounts for these advances.

Methodologically, we generate a pair of recursive forecasts of GDP growth $\mathrm{h}$-quarters $(\mathrm{h}=$ 1, 2, 4, 8) ahead over two alternative out-of-sample forecast periods (1974:2-1984:4 and 1985:12004:4) determined endogenously, as explained below. The first forecast is based on an unrestricted autoregressive distributed lag (ARDL) model that includes a financial variable and the second is based on a restricted AR model that excludes the financial variable. Each ARDL forecast is then evaluated against the benchmark AR forecast using two alternative out-of-sample testing procedures for nested models. In view of their known size and power properties, we select the MSE-F test of Diebold-Mariano/West from the traditional minimum MSFE-based testing strategy and the ENC-NEW test of Clark and McCracken $(2001,2005)^{3}$ from the more recent encompassing testing strategy. We consider a financial variable a consistently reliable indicator of future output growth provided the ARDL forecast based on the variable exhibits robustness both with respect to the alternative testing strategies and also with respect to the alternative forecast periods.

Model stability is an essential prerequisite for the accuracy of out of sample forecasts. We analyze of the timing, frequency and the direction of structural changes in both the mean and variance of the ARDL and AR models that are used to generate the forecasts of output growth, using both non-parametric and parametric statistical procedures. The results are checked for robustness with respect to multiple structural changes (Bai and Perron 1998, 2003) and also the

\footnotetext{
${ }^{3}$ The MSE-F is a variant of the MSE-T statistic of Diebold and Mariano (1995) and West (1996) but has greater power. The ENC-NEW statistic has greater power over the MSE-F statistic Clark and McCracken (2001).
} 
nonlinearities of the business cycle, using previously documented turning points (Cross, 1996) to define recessions and expansions in our sample. We find robust evidence of a significant decline in trend growth since 1974:1 and possibly three breaks in the conditional volatility of Canada's GDP growth based on linear models. But, once business cycle asymmetry is accounted for, two of the three breaks disappear, while the timing of the remaining significant volatility break is highly concentrated around 1973-74 across all models. Our findings suggest that the adverse productivity growth effects of the oil price shocks and the stabilizing influences of the shift from fixed to the flexible exchange rate monetary regime in the early 1970s are vital for a proper accounting of structural changes in Canada's GDP growth process.

The estimated timing of the mean break most common across various models is then used to achieve an endogenous division of our sample into an in-sample (1961:1-1974:1) and an out- ofsample (1974:2-2004:4) portion and a further division of the out of sample period into two subperiods (1974:2-1984:4; 1985:1-2004:4). This procedure helps minimize forecast bias which is important for a correct interpretation of the MSE-F and the ENC-NEW tests. If the forecasts are unbiased, both these tests can detect whether or not the ARDL forecast associated with a financial variable is significantly better than the benchmark AR forecast in the minimum MSFE sense. But, in presence of forecast bias, the MSE-F statistic is biased in favour of the restricted (AR) forecast and the ENC-NEW statistic is biased in favour of the ARDL forecast (Rogoff and Stavrakeva, 2008). Thus, a significant ENC-NEW may not necessarily imply that the ARDL forecast is better than the AR forecast in the minimum MSFE sense; instead it may imply that the rival AR and ARDL forecasts may be combined to form a new forecast that outperforms the restricted (AR) forecast in the minimum MSFE sense. In light of these new developments, we report estimates of forecast bias and the weights assigned to the unrestricted ARDL forecasts in the formation of optimal combined forecasts for all cases where the ENC-NEW statistic is statistically significant. Our results show that forecast bias may not be the source of the conflict between these tests.

We also find that the Canadian economy has been subject to widespread structural changes in the relationships between output growth and financial variables. Akin to the Rapach-Weber 
finding for the US economy, the out of sample forecasting abilities of most financial variables for Canada's output growth have markedly deteriorated, but not completely eliminated, after 1984:4. But unlike the US evidence, all term spread variables, both at the short and long end of Canada's yield curve, exhibit a more stable relationship to output growth and are more informative about future output growth than other financial instruments. Most importantly, the 1-3 year term spread (1-3 year government of Canada bond yield minus the 3-month commercial paper rate $\left.{ }^{4}\right)$ emerges from our analysis as having indicator properties that are consistently reliable at the 1 and 2 quarter forecast horizons and also exhibits a significant ability to forecast output growth at the 8 quarter horizon.

Section 2 describes the models and the methodology of tests for the timing of a single structural change. Section 3 describes our dataset and reports results of structural change and their robustness to model specification, multiple breaks and business cycle asymmetry. Section 4 describes the out-of-sample forecast evaluation methodologies and reports the results of our forecast evaluation. Section 5 concludes the paper.

\subsection{Models, Methodology and Tests of Structural Change}

Our analysis of the out-of-sample predictive ability of individual financial variables for Canada's real GDP growth is based on ARDL models of the form,

$$
z_{t+h}=\mu+\sum_{i=0}^{q_{1}} \alpha_{i} \Delta y_{t-i}+\sum_{i=0}^{q_{2}} \beta_{i} \Delta x_{t-i}+\varepsilon_{t+h}
$$

where the variable being predicted at time $t, z_{t+h}$, denotes the cumulative quarterly real GDP growth rate over the forecast horizon $\mathrm{h}($ for $\mathrm{h}=1,2,4,8)$ and is defined as ${ }^{5}, z_{t+h}=\sum_{i=1}^{h} \Delta y_{t+i}$, $\Delta y_{t}=y_{t}-y_{t-1}$ and $\mathrm{y}_{\mathrm{t}}$ is the natural logarithm of real GDP at time $\mathrm{t}$. The right hand side variable $\Delta x_{t}$ is a stationary financial variable whose predictive ability for GDP growth is being assessed,

\footnotetext{
${ }^{4}$ The results are the same when term spreads are defined using the 3-month t-bill rate.

${ }^{5}$ Rapach and Weber (2004) use the specification given by equation (1), while Stock and Watson (2003) redefine $z_{\mathrm{t}+\mathrm{h}}$ as $z_{t+h}=(400 / h) \sum_{i=1}^{h} \Delta y_{t+i}$.
} 
and $\varepsilon_{t+h}$ is a disturbance term. For $\mathrm{h}>1, z_{t+h}$ will be overlapping and so the errors $\varepsilon_{t+h}$ will be serially correlated. To account for this serial correlation, all estimation done this paper uses the Newey and West $(1987,1994)$ heteroskedasticity and autocorrelation-consistent (HAC) covariance estimator.

Prior to using model (1) for forecasting GDP growth out of sample, it is important to examine its structural stability over the full sample. To prepare model (1) for tests of structural stability over the full sample, we lag it by one period, set $\mathrm{h}=1$ and choose the best lag structure $\left(\mathrm{q}_{1}, \mathrm{q}_{2}\right)$ using the SIC criterion. The estimated lag order for most of the financial variables is $q_{1}=1, q_{2}=2$ (see column 2 of Table 2 ), so that the typical ARDL model whose structural stability we analyze in this paper is of the form,

$$
\Delta y_{t}=\mu+\alpha \Delta y_{t-1}+\beta_{1} \Delta x_{t-1}+\beta_{2} \Delta x_{t-2}+\varepsilon_{t}
$$

We document the timing, frequency, magnitude and the direction of structural changes in the parameters $\mu, \alpha, \beta_{1}, \beta_{2}$ (conditional mean) and in the size of the residual shocks $\varepsilon_{t}$ (conditional volatility) of Canada's GDP growth based on model (2) and also the nested (AR) model (Model 2 with $\beta_{1}=\beta_{2}=0$ ) used in previous studies. We also report evidence of structural changes in the unconditional mean and unconditional volatility of GDP growth ${ }^{6}$ based on the constant-growth model $\Delta y_{t}=\mu+\varepsilon_{t}\left(\right.$ Model 2 with $\left.\alpha=\beta_{1}=\beta_{2}=0\right)$.

\subsection{Timing of a Structural Change in Conditional Mean Growth}

We first test for a single instantaneous structural change in the parameters $(\mu, \alpha, \beta, \gamma)$ of the conditional mean of GDP growth using model (2). Let $W_{T}(k)$ denote the heteroskedasticity- and autocorrelation consistent Wald test of the null hypothesis of no structural change $\left(H_{0}: \mu_{11}=\mu_{12}, \alpha_{11}=\alpha_{12}, \beta_{11}=\beta_{12}, \beta_{21}=\beta_{22}\right)$ in the regression

\footnotetext{
${ }^{6}$ Observed changes in unconditional volatility may arise either from structural changes in conditional volatility or conditional mean or both. See Kim and Nelson (1999).
} 


$$
\begin{array}{r}
\Delta y_{t}=\left(\mu_{11}+\alpha_{11} \Delta y_{t-1}+\beta_{11} \Delta x_{t-1}+\beta_{21} \Delta x_{t-2}\right)\{1-I(t>k)\}+ \\
\left(\mu_{12}+\alpha_{12} \Delta y_{t-1}+\beta_{12} \Delta x_{t-1}+\beta_{22} \Delta x_{t-2}\right)\left\{I(t>k\}+\varepsilon_{t}\right. \\
t=1,2, \ldots \ldots . ., T .
\end{array}
$$

where $\mathrm{T}$ is the sample size, $\mathrm{k}$ is the break date for the parameters of conditional mean growth, and I(A) is an indicator function for the event A. Since the parameter $k$ appears only under the alternative hypothesis but not under the null hypothesis, the tests of equality of the coefficients $\left(H_{0}: \mu_{11}=\mu_{12}, \alpha_{11}=\alpha_{12}, \beta_{11}=\beta_{12}, \beta_{21}=\beta_{22}\right)$ do not have standard asymptotic properties. Andrews (1993), therefore, considers the function $\mathrm{F}_{\mathrm{T}}(\mathrm{k})$, defined as the Wald, LM or LR statistic, which tests the null hypothesis of no structural change for each possible value of $\mathrm{k}$ in the sample. Using the supremum mapping, Andrews (1993) derives the asymptotic properties of the statistic,

$$
\sup _{T_{1} \leq k \leq T_{2}} F_{k}=\sup F_{T}(k)
$$

where $\mathrm{T}_{1}=\pi \mathrm{T}$ and $\mathrm{T}_{2}=(1-\pi) \mathrm{T}$ and the trimming parameter is set at $\pi=0.15$. In this test, the value of $\mathrm{k}$ that maximizes $\mathrm{F}_{\mathrm{T}}(\mathrm{k})$ is the estimated date of the break point.

A limitation of the SupF statistic is that a structural break detected by the test could either refer to a break in the parameters of model (2) or a break in the distribution of the financial variable, $\Delta x_{t}$. To help avoid this uncertainty in the interpretation of the SupF test, Hansen (2000) recommends generating the $\mathrm{p}$ values for the test using his fixed-regressor bootstrap procedure. We use this procedure in this paper. It allows for heteroskedasticity in the error structure and is robust to general nonstationarities in the regressors, including mean and variance breaks and unit roots ${ }^{7,8}$.

\subsection{Timing of a Structural Change in Conditional Variance}

To test for a structural change in the conditional volatility of GDP growth using model (2), we apply the fixed-regressor bootstrap statistic to test for a break in the constant of the regression

\footnotetext{
${ }^{7}$ In the fixed-regressor bootstrap method, all regressors including the lagged dependent variables are held fixed in the simulation.

${ }^{8}$ We wish to thank David E. Rapach and Mark E. Wohar (2006) whose Gauss codes, available at http://pages.slu.edu/faculty/rapachde/Research.htm, we modify for use in this paper.
} 


$$
\sqrt{\frac{\pi}{2}}\left|\hat{\varepsilon}_{t}\right|=\delta+u_{t}
$$

where $\sqrt{\frac{\pi}{2}}\left|\hat{\varepsilon}_{t}\right|$ is an unbiased estimator ${ }^{9}$ of the conditional standard deviation of GDP growth and $\left|\hat{\varepsilon}_{t}\right|$ are absolute values of the estimated residuals from model (2). We also test for a structural break in the conditional standard deviation after allowing for a structural break in the conditional mean growth. To implement this test, we follow the work of Sensier and van Dick (2004) and consider model (2) with a single structural change at time $\mathrm{k}$,

$$
\begin{array}{r}
\Delta y_{t}=\alpha_{10}+\beta_{11} \Delta y_{t-1}+\gamma_{11} \Delta x_{t-1}+\delta_{11} \Delta x_{t-2}\{1-I(t>k)\}+ \\
\alpha_{20}+\beta_{21} \Delta y_{t-1}+\gamma_{21} \Delta x_{t-1}+\delta_{21} \Delta x_{t-2}\left\{I(t>k\}+\varepsilon_{t}\right.
\end{array}
$$

where $\varepsilon_{t}$ is a martingale difference sequence with time-varying conditional variance

$E\left[\varepsilon^{2}{ }_{t} \mid \Omega_{t-1}\right]=\sigma^{2}{ }_{t}$, where $\sigma_{t}=\sigma_{1}\{1-I(t>v)\}+\sigma_{2} I(t>v)$. Model (6) allows the break date $\mathrm{v}$ in the conditional variance to differ from the break date $\mathrm{k}$ in the conditional mean. To implement this test, we first estimate the residuals $\hat{\hat{\varepsilon}}$ from (6) by using the separate parameter estimates for the two regimes defined by of value of $\hat{k}$ that maximizes the $\operatorname{SupF}_{\mathrm{T}}(\mathrm{k})$ statistic, and then apply the bootstrapped SupF test to equation (5), with the dependent variable redefined as $\sqrt{\frac{\pi}{2}}\left|\hat{\hat{\varepsilon}}_{t}\right|$.

\subsection{Dataset and Empirical Results}

Our choice of financial indicators for Canada's GDP growth is influenced by several extant studies on the subject (Chan, et al. 2005; Dufour and Tessier, 2006; Duguay, 1994; Harvey 1997; Hassapis, 2003, Stock and Watson, 2003, Siklos and Barton 2001). Following these studies, we consider a set of 14 financial variables composed of changes in 6 different short and long term real

${ }^{9}$ Davidian and Carroll (1987) have shown that if the errors $\varepsilon_{t}$ are normally distributed, then $\sqrt{\frac{\pi}{2}}\left|\hat{\varepsilon}_{t}\right|$ represents an unbiased estimator of conditional standard deviation of GDP growth in model (2). 
interest rates, 4 term spreads and a default spread ${ }^{10}$, changes in real Canada-US real exchange rate, growth in real M1 money, and growth in real TSE-300 stock prices. The interest rate variables include changes in the real bank rate, real 3-month commercial paper rate, real 3-month t-bill rate, real 1-3 year, 3-5 year, and over 10 year Government of Canada bond yields. The term spreads comprise of the difference between annualized returns on 1-3 year, 3-5 year, 5-10 year and over 10 year Government of Canada bond yields and the 3-month t-bill rate, respectively. The default spread is the difference between the 3-month Commercial Paper rate and the 3-month t-bill rate.

The raw data were either quarterly or monthly and were converted to quarterly frequency to match the frequency of Canada's real GDP - the forecasted variable. Data are seasonally adjusted using the one-sided lag operator. Each series is checked for unit roots using the ADF test. All real interest rate levels, log level of real M1 money, log level of real stock prices were found to contain a unit root and were first differenced once to induce stationarity ${ }^{11}$. All interest rate spreads were found to be stationary, implying that the levels of the long and short term interest rates are cointegrated. All data came from the Statistic Canada's CANSIM data base.

\subsection{Replicating the Extant Evidence}

We first try to replicate the existing evidence of structural change in Canada's output growth.

Figure 1 plots the quarter-to-quarter fluctuations in Canada's real GDP growth over our full sample 1961:1-2004:4. The plot indeed shows that Canada's output growth has become less volatile since 1991:1 (McConnell and Perez-Quiros, 1998) and may also have undergone a decline in trend growth since 1974:1 (Fang, Miller and Lee, 2008). But Figure1 also appears to show that there may be additional volatility breaks around the early 1970 s and the early1980s.

We begin by applying some preliminary non-parametric tests for mean and variance instability (McConnell and Perez-Quiros, 2000) to Canada's GDP growth, and report the results in Table 1. A regression of GDP growth on a constant and time trend yields a significant negative

\footnotetext{
10 The theoretical grounds for the predictive power of the yield spread for output growth is explained by Berk (1998) while its empirical relevance is noted by many others, including Estrella and Trubin (2006).

${ }^{11}$ To save space, the unit root test results are not reported in the paper. They will be made available upon request.
} 
coefficient on the time trend with t-ratio $=-3.5$, suggesting a possible decline in trend growth (col.1). The sign and the significance of the coefficient on the trend term are robust to the inclusion of a lagged dependent variable (col.2) and also to the first difference of GDP growth (col.3). Similarly, a regression of the square of GDP growth on a constant and a time trend yields a significant negative coefficient on the time trend with t-ratio $=-4.9$, suggesting a possible reduction in the volatility of Canada's output growth (col.4). Again the sign and the significance of the coefficient on the trend term are robust to the inclusion of a lagged dependent variable (col.5) and also to the substitution of the absolute value of GDP growth for the square GDP growth as the dependent variable.

Next, we remove the mean of real GDP growth and perform the CUSUM and CUSUMSQ tests on the residuals. The CUSUM statistic is based on the cumulative sum of one-step-ahead standardized residuals from recursive estimation. Figure 2 shows that this statistic goes outside the area between the two critical lines, indicating instability in the parameters of mean growth. The CUSUMSQ statistic measures the cumulative sum of squares of the one-step-ahead recursive residuals, standardized to end at 1.0. If the squared residuals are roughly the same throughout the data set, then CUSUMSQ will tend to hug the straight line shown in Figure 3. Variance instability is indicated in Figure 3 by the maximum gap between the line and the cumulative sum of squares, in the early 1990 s, early 1980 s, and mid-1970s.

To pin down the timing of structural changes in the unconditional mean and variance of Canada's GDP growth, we apply the bootstrapped SupF test described above to regression (5) but with the dependent variable replaced, respectively, by the quarterly GDP growth rate $\Delta y_{t}$ and the normalized absolute values of the demeaned growth rates $\sqrt{\frac{\pi}{2}}\left|\Delta y_{t}-\hat{\mu}\right|$, where $\hat{\mu}$ is the fullsample mean of GDP growth. The results of the tests are reported in panel B of Table 1. Clearly, the bootstrapped SupF test easily detects (with p-value $=0$ ) a significant drop in unconditional mean of GDP growth in 1974:1, and also a drop in unconditional volatility in 1992:2. We also test for a break in unconditional standard deviation of GDP growth after imposing the estimated break 
in unconditional mean growth in 1974:1; only the timing of the break in unconditional volatility changes from 1992:2 to 1991:1, but not its existence. Finally, we try to determine the timing of structural changes in the conditional mean and volatility of GDP growth based on the AR characterization of growth (Eqn 2 with $\beta_{1}=\beta_{2}=0$ ). The results show (see panel C of Table 1) that the estimated break dates are very similar to those reported in panel B of Table 1. In summary, the preliminary evidence presented here seems to be quite consistent with the findings of previous studies cited above. But the evidence also points to the possibility of multiple volatility breaks in Canada's GDP growth process.

\subsection{Robustness to Model Specification}

Our first robustness check of the existing evidence (replicated in Table 1) is with respect to model specification. We augment the AR characterization of growth with a financial indicator of Canada's GDP growth to an ARDL model of the form (2) and apply the bootstrapped SupF test for structural change in the conditional mean and standard deviation of growth based on the model. Table 2 reports the test results for each financial variable. The first three columns of Table 2 report the goodness-of-fit statistics for each ARDL model (and also the AR model for comparison): the SIC-selected lag orders $\left(\mathrm{q}_{1}, \mathrm{q}_{2}\right)$, adjusted $\mathrm{R}^{2}$, and Rossi's (2005) optimal test of structural stability and Granger causality between GDP growth and each financial variable. Column (2) shows that, compared to the adjusted $R^{2}$ of 0.08 for the AR model, the addition of a financial variable results in varying degrees of improvement in model fit ( $\bar{R}^{2}$ ranging between 0.09 to 0.18$)$, with the greatest improvement occurring in the cases of the four term spread (1-3 yr, 3-5 yr, 5-10 yr and 10

$\mathrm{yr}^{+}$term spreads) variables, and the least improvement occurring for the default spread (DSP) and changes in the real exchange rate. The performances of changes in all real interest rates, real M1 money growth and growth in real stock prices fall in between, with changes in longer-term real interest rates generally performing better than changes in short-term rates. 
Rossi's (2005) $Q L R^{*}{ }_{T}$ statistic, reported in column (3), provides further insight into the information content of each financial variable for Canada's GDP growth. The $Q L R^{*}{ }_{T}$ statistic is an optimal test of the joint null hypothesis that the coefficients of the financial variable in the ARDL model are individually constant and equal zero, against the one-sided (upper tail) alternative hypothesis that these coefficients are nonzero for at least part of the full sample. It is a test of no Granger causality between GDP growth and the financial variable, which is robust to the presence of structural changes in the parameters attached to the financial variable. The null hypothesis is easily rejected for each financial variable, except for changes in the real Canada-U.S. exchange rate, revealing that each financial variable, especially the four term spreads, contains a significant amount of information about Canada's real GDP growth rate.

Columns 4, 5 and 6 of Table 2 report the SupF test results for a structural break in the conditional mean of each model, where the reported p values are generated with Hansen's (2000) fixed-regressor bootstrap. The results show that the ARDL models associated with changes in each of the short and long term real interest rates, growth in real M1 money, growth in real stock prices, changes in the real exchange rate and the default spread, has been subject to a structural break in conditional mean at the 5\% significance level or less. Interestingly, the SupF test fails to reject stability of the ARDL model associated with all four term spread variables at the 5\% significance level, but for three of the term spreads it detects a significant break at the $10 \%$ level. Thus, it appears that adding a term spread to the AR growth model induces some degree of stability to the model. Compared to the break in the conditional mean of GDP growth in 1974:1 for the AR model, the break date for the ARDL model associated with changes in the real bank rate, the 3 month real t-bill rate, the real10-year+ bond yield, and the growth in real stock prices is moved to the late1970s or early-1980s, and for M1 money growth to 1990:1. The size of the decline in conditional mean growth ranges from 40.0 to 48.4 percent across all models.

The final three columns of Table 2 report the bootstrapped SupF test results for a structural change in the residuals (conditional volatility) from each model, while maintaining that a break in 
conditional mean growth has occurred at the date shown in column (5) of Table 2. As in the case of the AR model, a significant break in conditional volatility is detected for each ARDL model. The primary effect of adding a financial variable to the AR model is in the timing, not existence, of the break: for 9 of the financial variables, the timing of the volatility reduction is moved from 1991:1 to the late 1980 s and for the remaining 5 variables, the volatility break date remains unchanged at 1991:1. We, therefore, conclude that the findings documented in previous studies of a significant drop in the mean and in the volatility of Canada's GDP growth are quite robust to changes in model specification.

\subsection{Multiple Structural Changes}

As our second robustness check, we examine the possibility of multiple structural changes. Recent evidence has shown that many U.S macroeconomic time series may have undergone multiple volatility breaks (Sensier and van Dijk, 2004; Jin and Miljkovic, 2010) and also that tests of a single structural change such as the SupF test may have low power in the presence of multiple breaks (Bai, 1997). To address these issues, we apply the sequential Bai and Perron (1998; 2003), henceforth BP methodology - to test for multiple structural changes in the (un)conditional mean and volatility of Canada's GDP growth.

The first step in this methodology is to test for model stability. We test for model stability by applying the $\mathrm{BP}(1998)$ double maximum $\mathrm{UD}_{\max }$ and $\mathrm{WD}_{\max }$ test statistics, each of which tests the null hypothesis of zero breaks against the alternative hypothesis of an unknown number of breaks, up to a maximum of five breaks ${ }^{12}$. If zero breaks are rejected then, in the next step, the number of breaks is determined by sequentially applying the BP (1998) $\operatorname{SupF}_{\mathrm{T}}(\ell+1 \mid \ell) \operatorname{statistic}^{13}$ for $\ell=0$, 1, 2, 3, 4. If $\operatorname{SupF}_{T}(2 \mid 1)$ is insignificant, then we may conclude that there is only one structural break. If the $\operatorname{SupF}_{T}(2 \mid 1)$ statistic is significant, then we examine the $\operatorname{SupF}_{T}(3 \mid 2)$ statistic. This

\footnotetext{
12 The second of these, the $\mathrm{WD}_{\max }$ statistic, applies different weights to the individual $\mathrm{UD}_{\max }$ statistics so that the marginal p-values are equal across values of m; see BP (1998) for details.

${ }^{13}$ It should be noted that the $\operatorname{SupF}_{T}(1 \mid 0)$ statistic is similar to Andrews's (1993) SupF statistic, and may have low power in the presence of multiple breaks.
} 
procedure is repeated until no further significant break is detected or until a maximum of five breakpoints are detected or until the subsamples become too small for further splitting. Throughout, we require a minimum of $15 \%$ of the sample to lie between consecutive breaks and generate pvalues using Hansen's (2000) fixed-regressor bootstrap.

Table 3 reports the results for tests of multiple breaks in (un)conditional mean of Canada's GDP growth. For breaks in unconditional mean, we apply the BP procedure described above to the constant-growth model $\Delta y_{t}=\mu+\varepsilon_{t}$ (Model 2 with $\alpha=\beta_{1}=\beta_{2}=0$ ) and for breaks in the conditional mean the procedure is applied to the parameters of the AR model (Model 2 with $\beta_{1}=\beta_{2}=0$ ) and each of the ARDL models (2). Focusing first on breaks in unconditional mean, both the $\mathrm{UD}_{\max }$ and the $\mathrm{WD}_{\max }$ statistics reject the null hypothesis of zero breaks at the $5 \%$ level or less, indicating the presence of at least one break. Then the sequential application of the $\operatorname{SupF}_{T}(l+1 \mid l)$ statistics (for $\left.\mathrm{i}=0,1,2,3,4\right)$ reveals that only the $\operatorname{SupF}_{T}(0 \mid 1)$ statistic is significant at the $5 \%$ level, confirming a single structural break in the unconditional mean in 1974:1. The results for breaks in conditional mean growth based on the AR model confirms a single break in 1974:1. A single break in conditional mean is also confirmed by each of the ARDL models. Furthermore, for the ARDL models associated with changes in the real CP rate, the 1-3 year, 3-5 year, the 5-10 year bond yields, the default spread, and changes in the real exchange rate, the timing of the break is unchanged at or near1974:1; for each of the term-spreads the break date is moved forward to the late 1970 s or early 1980s. In the case of the real M1 money growth, the break date is moved to 1990:1, which is consistent with the finding of Chan et al. (2005).

Table 4 reports the results for tests of multiple breaks in (un)conditional volatility of Canada's GDP growth ${ }^{14}$. For breaks in unconditional and conditional volatility, we apply the BP procedure, respectively, to the absolute value of the demean growth rates and to the residuals of the AR and of each of the ARDL models reported in Table 3. The results are quite remarkable. Turning to breaks in unconditional volatility (UV) in Table 4 , each of the $\mathrm{UD}_{\max }, \mathrm{WD}_{\max }$ statistics rejects the null

\footnotetext{
${ }^{14}$ Because of their close similarity of the results to those reported in Table 4, the results for a few of the financial variables are not reported in Table 4, in order to save space.
} 
hypothesis of zero breaks at the $5 \%$ significance level or less, and among the $\operatorname{SupF}_{T}(l+1$

|l) statistics, the $\operatorname{SupF}_{T}(3 \mid 2)$ is significant, indicating the presence of three possible breaks in unconditional volatility. The $90 \%$ confidence intervals for the breaks are also fairly tight. The timing and direction of the these breaks consist of an initial drop in output volatility in 1973:2, followed by a rise in output volatility in 1980:2, and a final drop in output volatility in 1992:2. The timing of these volatility breaks seems quite consistent with the evidence in Figure 1, and as reported under UV-M in Table 4, they are also robust to the allowance for the break in mean growth in 1974:1. Furthermore, the procedure also detects the same three breaks in conditional volatility of GDP growth based on the residuals of the AR model. Each of the ARDL models also detects three breaks in conditional volatility, at the $10 \%$ significance level or less, with only minor differences in the timing of the breaks across the various ARDL models.

\subsection{Business Cycle Asymmetry}

As our third robustness check we examine whether business cycle asymmetry can explain the multiple volatility breaks found in linear models of GDP growth. The timings of the volatility breaks estimated in this paper seem to roughly coincide with the turning points for the Canadian economy (Cross, 1996), raising the possibility that these breaks may not be truly structural. To see whether neglected business cycle nonlinearity can explain the volatility breaks, we allow the parameters of the AR and each of the ARDL models to differ in expansions and recessions, using the turning points from Cross (1996) to define recessions and expansions in our sample. To illustrate this testing procedure using the simpler AR model we write the model as,

$$
\Delta y_{t}=a_{0}+b \Delta y_{t-1}+a_{1} D+b_{1} D \Delta y_{t-1}+\varepsilon_{t}
$$

where $\mathrm{D}=1$ if recession, 0 otherwise and where periods of Canadian recessions (1969:3-1970:1, 1979:4-1980:2, 1981:1-1982:3, and 1989:4-1990:4) are taken from Cross (1996). The heteroskedasticity-robust least squares estimation of (7) yields: $\hat{a}_{0}=0.894,(p=0.00)$, $\hat{b}=0.126(p=0.10), \hat{a}_{1}=-1.18(p=0.00)$, and $\hat{a}_{1}=0.307(p=0.11)$. These estimates 
imply that the annualized conditional mean of GDP growth is $4.08 \%$ in expansions compared to $1.10 \%$ in recessions; the annualized conditional standard deviation of GDP growth of $3.08 \%$ in expansions, compared to $2.39 \%$ in recessions. In addition, negative growth in recessions is more persistent $\left(\hat{b}+\hat{b}_{1}=0.43\right)$ than positive growth in expansions $(\hat{b}=0.13)$. Given these business cycle asymmetries captured in model (7), we apply the bootstrapped BP (1998) test procedure to the normalized absolute values of residuals from model (7). We repeat this procedure for the ARDL model (2) associated with each financial variable.

Table 5 reports the results of BP (1998) tests after accounting for business cycle asymmetry. It is evident from Table 5 that, when business cycle non-linearity is accounted for, two of the three volatility breaks observed in linear models disappear. Furthermore, the timing of the remaining significant volatility break across all conditional models is highly concentrated in the period 1973:1-1973:4, which is close to the timing of the break in the conditional mean growth in 1974:1 found in the models. This evidence is also consistent with Fang, Miller and Lee (2008) who using a GARCH specification find evidence of a mean break in 1974:1 and a break in the residual variance in 1987:1. In sum, the evidence from Table 5 continue to support our overall finding of widespread structural changes in relationships between Canada's GDP growth and financial variables; term spread variables generally exhibit a more stable relationship to output growth and are also more informative about output growth than other financial instruments. The evidence of decline in Canada's trend growth since 1974:1 is quite robust but that of a decline in conditional volatility since 1991:1 is not robust. The results show that both the (un)conditional mean and volatility of Canada's GDP growth may have declined around 1973-74.

\subsection{Simulated Out-of-sample Forecasts: Evaluation Strategies}

We now turn to an evaluation of the reliability of the out-of-sample forecasting ability of individual financial variables for Canada's GDP growth. To qualify as an out-of-sample forecast, a forecast in period $t$ must be a function only of information available in period $t-h$ where $h$ is the forecast horizon. We generate such forecasts of Canada's GDP growth by estimating each unrestricted 
ARDL model (1) and also the restricted (AR) model (Equation 1 with all $\beta_{i}=0$ ) with ordinary least squares, using the first $\mathrm{R}$ of the $\mathrm{T}$ observations in our sample. To minimize forecast bias arising from structural breaks in the forecast period, we chose the date $\mathrm{R}$ which separates the insample (1961:2-1974:1) from the out-of-sample (1974:2-2004:4) portion of our sample so that it coincides with the estimated structural break date for the mean of GDP growth. Using the parameter estimates, respectively, for the ARDL and the AR models and the observations for $\Delta x_{R-i}\left(i=0, . ., q_{2}-1\right)$ and $\Delta y_{R-i}\left(i=0, . ., q_{1}-1\right)$, we construct a pair of $\mathrm{h}$-step-ahead (for $\mathrm{h}=1,2$, $4,8)$ forecasts for $Z_{R+h}$, one for each model. Next we add one more observation to the estimation period and using the $\mathrm{R}+1$ observations re-estimate the parameters of both models, and generate another pair of h-step-ahead forecasts, one for each model. This process is repeated until we reach the end of the sample, leaving us with T-R-h+1 recursive out-of-sample forecasts, one for the unrestricted model and one for the restricted model.

Next we compare each ARDL forecast against the benchmark AR forecast using both the MSE-F and the ENC-NEW statistics. Suppose the h-step-ahead forecast errors from the unrestricted ARDL and the restricted AR models are $\left\{\hat{\varepsilon}_{1, t+h}\right\}_{t=R}^{T-h}$ and $\left\{\hat{\varepsilon}_{0, t+h}\right\}_{t=R}^{T-h}$ respectively. Then the MSE-F and the ENC-NEW statistics for evaluating the h-step-ahead forecasts are constructed as follows:

$$
\begin{aligned}
& \operatorname{MSE}-\mathrm{F}(\mathrm{h})=(T-R+h+1) \frac{M \hat{S F E} E_{0}(h)-M \hat{S} F E_{1}(h)}{M \hat{S F E} E_{0}(h)} \\
& \operatorname{ENC-NEW(h)}=(T-R-h+1) \times \frac{E\left(\hat{\varepsilon}_{0, t+h}\right)\left(\hat{\varepsilon}_{0, t+h}-\hat{\varepsilon}_{1, t+h}\right)}{M \hat{S F E} E_{1}(h)}
\end{aligned}
$$

where $\mathrm{MSFE}_{0}$ and $\mathrm{MSFE}_{1}$ are the mean square forecast errors for the restricted and unrestricted models respectively. The MSE-F statistic tests the null hypothesis of equal forecast accuracy $\mathrm{MSFE}_{0}=\mathrm{MSFE}_{1}$, so that MSE-F $=0$ under the null. Under the alternative hypothesis $M S F E_{1}<M S F E_{0}, M S E-F>0$, so that the MSE-F test is a one-sided (upper tail) test. In contrast, the ENC-NEW statistic tests the null hypothesis that the (additional) financial variable included in 
the ARDL model has no predictive ability for GDP growth. Under the null the population covariance between $\varepsilon_{0, t+h}$ and $\varepsilon_{0, t+h}-\varepsilon_{1, t+h}$ is zero and ENC-NEW $=0$. In this case, the restricted AR forecast is said to encompass the unrestricted ARDL forecast since the additional financial variable included in ARDL model is redundant. The alternative hypothesis is that the financial variable does have predictive power for GDP growth, implying that the covariance between $\varepsilon_{0, t+h}$ and $\varepsilon_{0, \mathrm{t}+\mathrm{h}}-\varepsilon_{1, \mathrm{th}}$ is positive and so the ENC-NEW $>0$, and then the restricted AR forecast does not encompass the unrestricted ARDL forecast ${ }^{15}$.

Comparing equations 8 and 9 it can be seen that if the AR and the ARDL model forecast errors have similar variances, $\mathrm{MSFE}_{0}=\mathrm{MSFE}_{1}$, and are approximately uncorrelated, $\sum \varepsilon_{1, t+h} \varepsilon_{0, t+h}=0$, then the MSE-F statistic will be zero and insignificant but the ENC-NEW statistic will be positive and may well be significant. In the absence of forecast bias, a significant ENC-NEW implies that the ARDL forecast has a significantly lower MSFE than the AR forecast, even when the MSE-F statistic is not significant. But caution must be exercised in interpreting a significant ENC-NEW when the forecasts being compared contain 'severe' forecast bias, as explained below.

\subsection{Forecast Results}

Table 6 reports the MSE-F and ENC-NEW statistics and their bootstrapped p-values (shown in parentheses) for Canada's real GDP growth for all 14 financial variables over the two out-ofsample periods at $\mathrm{h}=1,2,4$ and 8 -quarters-ahead forecast horizons. Table 6 also reports the lag orders $q_{1}$ and $q_{2}$ for equation (1) selected by SIC and the Theil's U metric, defined as $\mathrm{U}=$ $\frac{R M S E_{1}}{R M S E_{0}}$, where $\mathrm{RMSE}_{1}$ and $\mathrm{RMSE}_{0}$ are the root mean squared errors for the unrestricted and the

\footnotetext{
${ }^{15}$ Clark and McCracken (2004) show that, for $\mathrm{h}>1$, both the MSE-F and the ENC-NEW statistics have nonnormal and non-pivotal limiting distributions so that inferences must be based on bootstrap procedures. The bootstrap procedure we employ in the present study is a modification of the one used by Rapach and Weber (2004) which, in turn, is a variant of the procedure used by Clark and McCracken (2004). The Gauss code for the bootstrap procedure is available at http://pages.slu.edu/faculty/rapachde/Research.htm. For technical details about this procedure we refer the reader to these previous studies.
} 
restricted model forecasts, respectively. If $U<1$, then the unrestricted model forecast associated with a financial variable has a lower RMSE than that of the restricted model.

Turning first to the six interest rate variables, the evidence clearly indicates a general deterioration in the predictive ability of each variable after 1984:4 especially at the longer horizons $(\mathrm{h}=4,8)$. At the $\mathrm{h}=1$ and 2 horizons, none of the interest rate variables exhibits an ability to forecast GDP growth in either out-of-sample period, according both the MSE-F and the ENC-NEW statistics. The only exception is a change in the long-term real bond yield (10 Yr+ bond yield) for which ENC-NEW is significant at the $10 \%$ level or less, but not the MSE-F statistic. But, at the $\mathrm{h}=$ 4 and 8 horizons, changes in all short term real interest rates (bank rate, tbill3 rate, and CP3 rate) and also longer term (1-3 year, 3-5 year, 10 year $\left.^{+}\right)$bond yields exhibit a significant predictive ability in period 1974:4-1984:4 according to both tests, but this ability is sustained over the 1985:12004:4 only for changes in the real bank rate $($ at $\mathrm{h}=8)$, t-bill rate $($ at $\mathrm{h}=4,8)$, the $\mathrm{CP}$ rate $($ at $\mathrm{h}=4$, 8), 3-5 $\mathrm{Yr}$ bond rate $(\mathrm{at} \mathrm{h}=8)$ and the $10 \mathrm{Yr}+$ bond rate $(\mathrm{h}=8)$. In all other cases, only the ENCNEW is significant over the period 1985:1-2004:4, suggesting a weaker but still significant forecasting ability after 1984:4.

The evidence for the four term spread variables is especially interesting. At each of the $h=$ 1, 2 and 4 horizons, the $\mathrm{U}$ metric is always less than unity in both periods, suggesting that all four term spreads may contain useful leading information about GDP growth in both out-of-sample periods. But only the changes in the 1-3Yr term spread ( $a t h=1$ and 2 ), and the 3-5Yr term spread $($ at $\mathrm{h}=1$ ) have a consistently reliable ability forecast output growth in both forecast periods, according to both the MSE-F and ENC-NEW tests. In all other cases, only the ENC-NEW statistic is significant in the period 1985:1-2004:4 suggesting either that the forecasting ability of the variables has deteriorated (but remained statistically significant) after 1984:4 or, of the possibility of profitable forecast pooling. Interestingly, at the $\mathrm{h}=8$ horizon, the $\mathrm{U}$ metric is uniformly lower in the period 1974:4-1984:4 and also the ENC-NEW statistic is significant in the period 1985:12004:4 but not in 1974:4-1984:4, suggesting that the leading information content of all four term spreads for output growth may actually have improved after 1984:4. But the MSE-F statistic fails 
to confirm this finding. Unlike the term spreads, the default spread (DSP) contains no leading information about output growth at all.

The real M1 money growth exhibits a significant ability to forecast output growth at all four forecast horizons in period 1974:4-1984:4 according to both the MSE-F and the ENC-NEW statistics. But its forecasting ability has declined precipitously in period 1985:1-2004:4, as only the ENC-NEW statistic is significant at the $\mathrm{h}=1$ and 2 horizons in period, and also the fact that the Theil's $\mathrm{U}$ metric is always less than one $(\mathrm{U}<1)$ in the first but substantially greater than one $(\mathrm{U}>$ 1) in the second forecast period. A general instability in the predictive ability of Canada's M1 money growth has been reported by several previous Canadian studies noted in section 3.1 and also by a recent study for the U.S. economy (Choia et al., 2009). One possible reason for the decline in the predictive ability M1 money growth after 1985 is that the period 1985:1-2004:4 contains a known mean break in 1991:1 in the ARDL model associated with the M1 money growth (see Tables 3 and 5). When we recalculate the forecasting ability of real M1 money growth for the outof-sample sub-periods 1974:2-1991:1 and 1991:2-2004:4, the results (not reported) show that the real M1 money growth exhibits a significant ability to forecast Canada's GDP growth over the period 1991:2-2004:4 at $h=1$ and 2 horizons, according to both the MSE-F and the ENC-NEW statistics $^{16}$.

Perhaps not surprisingly, changes in the Canada-US real exchange rate exhibit no ability to forecast output growth in any period and at any horizon. Duguay (1994) and others have shown that a great deal of prior 'smoothing' is necessary before a significant effect of changes in the US-Canada real exchange rate on output growth emerges. By contrast, growth in real stock prices (TSE300) exhibits a significant ability to forecast Canada's GDP growth during 1974:2-1984:4 at $\mathrm{h}=1,2$ and 4 forecast horizons, according to both test statistics. But this ability is not robust after 1984:4, since only the ENC-NEW statistic is significant in the second forecast period (1985:1-2004:4), implying

\footnotetext{
${ }^{16}$ Chan, Djoudad, and Loi (2005), however, argues that the removal of reserve requirements and other changes between 1992 and 1994 have made demand and notice deposits indistinguishable and this has adversely affected the information content of M1 (currency plus demand deposits) but not of M1+ (M1 plus notice deposits) money aggregates.
} 
either a weaker ability to forecast GDP growth after 1984:4, or the possibility of optimal pooling.

We now examine more closely all those cases in Table 6 where the ENC-NEW statistic is statistically significant but the MSE-F statistic is not significant. These conflicts may arise either from the greater power of the ENC-NEW statistic or from the presence of 'severe' forecast bias. Rogoff and Stavrakeva (2008) show that in the regression, $Z_{t+h}=b \hat{z}_{1, t+h}$, where $z_{t+h}$ is the predicted variable and $\hat{Z}_{1, t+h}$ is the unrestricted ARDL forecast and $\mathrm{h}$ is the forecast horizon, if $0<\hat{b} \leq \frac{1}{2}$, then the ARDL forecast contains severe scale forecast bias (the forecast is unbiased if b equals 1). In such cases, a significant ENC-NEW does not necessarily imply that the ARDL forecast has a smaller MSFE than the AR forecast; rather it implies that there may exist an optimal combination of the ARDL and the AR forecasts such that the combined forecast has a smaller MSFE than the MSFE of the AR forecast. To illustrate, suppose we form an optimal composite out-of-sample forecast of $z_{t+h}$ as a linear combination of the out-of-sample restricted $\hat{z}_{0, t+h}$ and unrestricted $\hat{z}_{1, t+h}$ forecasts

$$
\hat{z}_{c, t+h}=\lambda \hat{z}_{1, t+h}+(1-\lambda) \hat{z}_{0, t+h}
$$

where $0 \leq \lambda \leq 1$. If $\lambda=0$, then the ARDL forecast does not contribute any new information to the formation of the optimal composite forecast beyond that already contained in the AR forecast. If $\lambda$ $>0$, then the ARDL forecast does contribute useful new information to the formation of the optimal composite forecast.

Table 7 reports the estimated value of $\mathrm{b}$ in the regression $z_{t+h}=b \hat{z}_{1, t+h}$ with standard errors shown in parentheses, the weight $\lambda$ attached to the ARDL forecast in equation (10), and also the metric U, the ratio of the optimal composite out-of-sample RMSFE to the restricted model out-ofsample RMSFE, for all cases in which the ENC-NEW statistic (in Table 6) is significant at the 10\% level in period 1985:1-2004:4. Clearly the estimate of $b$ is highly significant in all cases and the 
estimate always lies well outside the range $0<b \leq \frac{1}{2}$ of severe/significant forecast bias, implying that the conflict between the ENC-NEW and the MSE-F statistics observed in Table 6 may not be the result of severe forecast bias. This, in turn, implies that a significant ENC-NEW statistic in Table 6 may be interpreted to mean that the ARDL forecasts do have a significantly smaller MSFE than the MSFE for the AR forecast. But the estimated range $0.61 \leq b \leq 0.80$ which is quite a bit smaller than 1, may suggest the presence of some forecast bias in all cases, due perhaps to small sample. This may explain why the Theil's $U$ metric is generally less than one $(U<1)$ in Table 7 , indicating that the combined forecast has a smaller RMSFE compared to the RMSFE for the AR model. The relatively large estimates of the weights $\lambda$ attached to the ARDL forecasts in equation (10) denotes the quantitatively large contributions the ARDL forecasts make to the formation of optimal composite forecasts.

\section{Conclusions}

The paper addresses the difficulties that arise when attempting to extract and evaluate the reliability of the information content of financial variables for future output growth. We rely both on simple non-parametric, as well as, bootstrapped variants of robust parametric test procedures for determining the timing of structural changes in standard (AR and ARDL) models linking output growth to individual financial variable. The results are checked for robustness to multiple structural changes in mean and volatility of output growth and also to the non-linearity of the conditional mean growth over the business cycle. Our evaluation of the out-of-sample forecasting ability of each financial variable relies on alternative test procedures for comparing forecasts from nested models and over alternative forecast windows. We analyze the implications of forecast bias for the interpretation of the out-of-sample tests and for forecast pooling.

The results from our structural breaks analysis indicate that the evidence of a decline in Canada's trend growth around 1974:1 reported in previous studies is robust to changes in model specification, presence of multiple structural changes, and to the nonlinearities of the business 
cycle. But the finding of a significant moderation in the volatility of Canada's GDP growth since 1991:1 is not robust. Instead, we find that when multiple breaks and business cycle nonlinearity are duly accounted for, the timing of the decline in (un)conditional volatility roughly coincides with the timing of the break in trend growth around 1973-74.

The evidence from our simulated out-of-sample forecast analysis indicate that structural changes may have substantially weakened, but not completely eliminated, the ability of most financial variables to forecast Canada's output growth after 1984:4 - confirming that the Rapach-Weber finding for the US economy also generalizes to the Canadian economy. But unlike the extant US evidence, we find that several term spread variables, both at the short and long end of Canada's yield curve, exhibit a fairly stable relationship to output growth and are also more informative about future output growth than other financial instruments. Most importantly, the 1-3 year term spread emerges from our analysis as having indicator properties that are consistently reliable at the 1 and 2 quarter forecast horizons, and it also exhibits a significant ability to forecast output growth at the 8 quarter horizon. We also find that the real M1 money growth, which had experienced a dramatic decline in its information content for Canada's output growth over 1974:2-1991:1, has regained a significant ability to forecast output growth at the 1 and 2 quarter horizons after 1991:1 according to both the minimum MSFE and the encompassing testing strategies and can, therefore, perform a useful role as an information variable in the management of monetary policy in Canada. 


\section{References}

Andrews, D.W.K. (1993) Tests for parameter instability and structural change with unknown change point. Econometrica, 61, 821-56.

Bai, J. (1997) Estimation of a change point in multiple regressions. Review of Economics and Statistics, 79, 551-563.

Bai, J, Perron P. (1998) Estimating and testing linear models with multiple structural changes. Econometrics 66, 47-78.

Bai, J, Perron P. (2003) Computation and analysis of multiple structural change models. Journal of Applied Econometrics, 18, 1-22.

Berk, J.B. (1998) The information content of the yield curve for monetary policy: A Survey. De Economist, 146: 303-320.

Bernanke, B.S. (2004) What Policymakers can learn from asset prices. Federal Reserve Board, (April 15):http://www.federalreserve.gov/boarddocs/speeches/2004/20040415/default.htm

Bernanke, B.S and Boivin J. (2003) Monetary policy in a data-rich environment. Journal of Monetary Economics 50, 525-546.

Chan, T., Djoudad, R and Loi, J. (2005) Changes in the indicator properties of narrow monetary aggregates. Bank of Canada Review (Summer), 3-10.

Choia, K. and Jung, C. (2009) Structural changes and the U.S. money demand function. Applied Economics, Vol 41, Issue 10, 1251-1257.

Clark, T.E. and McCracken, M.W. (2001) Tests of equal forecast accuracy and encompassing for nested models. Journal of Econometrics, 105, 85-110.

Clark, T.E and McCracken, M.W. (2004) Evaluating long horizon forecasts. Manuscript, University of Missouri-Columbia.

Clark, T.E. and McCracken, M.W. (2005) The power of tests of predictive ability in the presence of structural breaks. Journal of Econometrics, 12, 1-31.

Cross, P. (1996) Alternative measures of business cycles in Canada: 1947-1992. Canadian Economic Observer, Statistic Canada, Catalogue No. 11-010-XPB

Cross, P. (2004) A Diffusion Index for GDP. Canadian Economic Observer. May, Statistics Canada.

Davidian, M. and Carroll, R.J. (1987) Variance function estimation. Journal of the American Statistical Association, 82, 1079-1091.

Diebold, F.X. and Mariano, R.S. (1995) Comparing predictive accuracy. Journal of Business and Economic Statistics, 13, 253-63.

Dufour, J.M. and Tessier, D. (2006) Short-run and long-run causality between monetary policy and stock prices. Bank of Canada Working Paper No 2006-39. 
Duguay, P. (1994) Empirical evidence on the strength of the monetary transmission mechanism in Canada: An aggregate approach. Journal of Monetary Economics, 33, 39-61.

Estrella, A. and Trubin, M.R. (2006) The yield curve as a leading indicator: Some practical issues. Current Issues in Economics and Finance, 12, Number 5.

Fang, W.S, Miller, S.M and Lee, C.S. (2008) Cross-country evidence on output growth volatility: Nonstationary variance and GARCH models. Scottish Journal of Political Economy, 55, 509-541.

Goodhart, C. and Hofmann, B. (2001) Asset prices, financial conditions, and the transmission of monetary policy. Paper presented for the conference on Asset prices, Exchange rates, and monetary policy, Stanford University, March 2-3.

Jin, H. J. and Miljkovic, D. (2010) An analysis of multiple structural breaks in U.S. relative farm prices. Applied Economics, Vol. 42, Issue 25, 3253-3265.

Kim, C.J and Nelson, C.R. (1999) Has the U.S. economy become more stable? A Bayesian approach on a Markov-switching model of the business cycle. The Review of Economics and Statistics, 81, 608-616.

Harvey, C.R. (1997) The relation between the term structure of interest rates and Canadian economic growth. The Canadian Journal of Economics, 30, 169-93.

Hassapis, C. (2003) Financial Variables and real activity in Canada. The Canadian Journal of Economics, 36, 421-442.

Hansen, B.E. (2000) Testing for structural change in conditional models. Journal of Econometrics, 97, 93-115.

McCracken, M.W. (2004) Asymptotics for out-of-sample tests of Granger causality. Manuscript, University of Missouri at Columbia.

McConnell, M.M and Perez-Quiros, G. (1998) Output fluctuations in the United States: What has changed since the early 1880s? Staff Reports (41, June), Federal Reserve Bank of New York

McConnell, M.M. and Perez-Quiros, G. (2000) Output fluctuations in the United States: What has changed since the early 1980s? The American Economic Review 90, 1464-1476.

Newey, W.K. and West, K.D. (1987) A simple, positive semi-definite, heteroskedasticity, autocorrelation consistent covariance matrix. Econometrica, 55, 703-708.

Newey, W.K. and West, K.D. (1994) Automatic lag selection in covariance matrix estimation. Review of Economic Studies, 61, 631-653.

Rapach, D.E. and Weber, C.E. (2004) Financial variables and the simulated out-of-sample forecastability of U.S. output growth since 1985: An encompassing approach. Economic Enquiry, $42,717-38$.

Rapach, D.E. and Wohar, M.E. (2006) Structural breaks and predictive regression models of aggregate U.S. stock returns. Journal of Financial Economics, 4, 238-274.

Ratnovsky, L. and Huang, R. (2009) Why are Canadian banks more resilient? IMF Working Paper: $\mathrm{WP} / 09 / 152$. 
Rogoff, K. and Stavrakeva, V. (2008) The continuing puzzle of short horizon exchange rate forecasting. NBER Working Paper No.14071, National Bureau of Economic Research, Inc.

Rossi, B. (2005) Optimal tests of nested model selection with underlying parameter instability. Econometric Theory 21, 962-990.

Sensier, M. van Dijk, D. (2004) Testing for volatility changes in U.S. Macroeconomic time series. The review of Economics and statistics, 86, 833-839.

Siklos, P.L. and Barton, A.G. (2001) Monetary aggregates as indicators of economic activity in Canada: Empirical evidence. The Canadian Journal of Economics, 34, 1-17.

Stock, J.H. and Watson, M.W. (2003) Forecasting output and inflation: The role of asset prices. Journal of Economic Literature, 41, 788-829.

West, K.D. (1996) Asymptotic inference about predictive ability. Econometrica, 64, 1067-1084. 

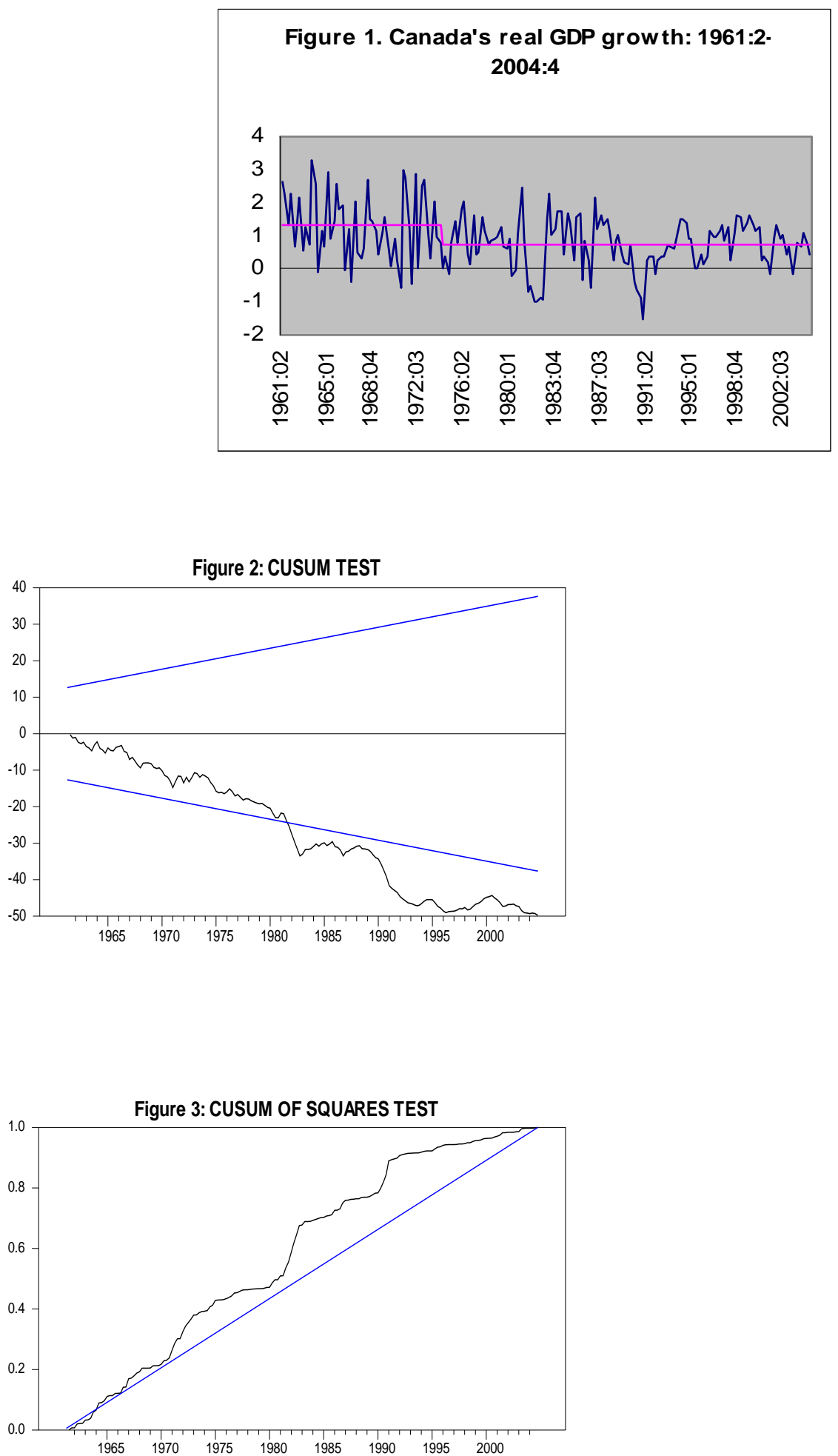
Table 1: Preliminary evidence of instability in mean and variance of Canada's real GDP growth ( $\Delta \mathrm{y})$ : 1961:2-2004:4

PANEL A: Non-parametric tests of instability in mean and variance of Canada's GDP growth $\begin{array}{cl}\text { Instability in Mean Growth } & \underline{\text { Instability in Variance }} \\ \text { Dependent variable } & \underline{\text { Dependent variable }}\end{array}$

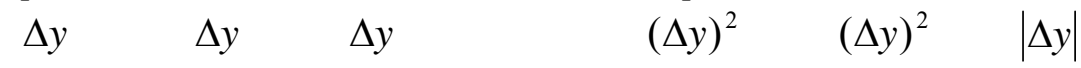
(1)
(2)
(3)
(4)
(5)
(6)

\begin{tabular}{lccccrr}
\hline Constant & 1.292 & 0.918 & 1.278 & 2.811 & 2.461 & 1.411 \\
& $(10.0)$ & $(5.8)$ & $(12.3)$ & $(9.7)$ & $(6.9)$ & $(13.6)$ \\
Trend & -0.005 & -003 & -004 & -0.014 & -0.012 & -0.004 \\
& $(-3.5)$ & $(-2.4)$ & $(-4.3)$ & $(-4.9)$ & $(-4.0)$ & $(-4.2)$ \\
\{Dependent & & 0.264 & & & 0.089 & \\
Variable\}-1 & $(3.6)$ & & & & \\
$\begin{array}{l}\Delta \text { (Dependent } \\
\quad \text { variable) }\end{array}$ & & & 0.495 & & & \\
$\mathrm{R}^{2}$ & & & $(9.8)$ & & & \\
DW & 0.07 & 0.13 & 0.40 & 0.12 & 0.12 & 0.09 \\
OBS & 1.5 & 2.0 & 0.7 & 1.8 & 2.0 & 1.7 \\
& 175 & 174 & 174 & 175 & 174 & 175
\end{tabular}

PANEL B: Structural change in unconditional mean and volatility of Canada's real GDP growth

Mean Break

Break $\quad$ Variance Break

$26.9 \quad 1974: 1 \quad-45 \%$

$(0.0)$

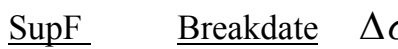

Variance Break Given Mean Break

$\underline{\text { SupF }} \quad \underline{\text { Breakdate }} \Delta \sigma$

33.3

$(0.0)$

PANEL C: Structural change in conditional mean and volatility of an AR model of growth: 1961:2-2004:4

$\begin{array}{lllllllll}29.9 & 1974: 1 & -- & 28.0 & 1991: 1 & -57.1 & 28.0 & 1991: 1 & -57.1 \\ (0.0) & & & (0.0) & & & (0.0) & & \end{array}$

Note: In panels B and C, p-values calculated using Hansen's (2000) fixed-regressor bootstrap are reported in parentheses and are highlighted to indicate their statistical significance at all conventional levels. 
Table 2: Tests of structural change in conditional mean and conditional volatility of Canada's real GDP growth, 1961:2 -2004:4

\begin{tabular}{|c|c|c|c|c|c|c|c|c|c|}
\hline \multirow[t]{3}{*}{ (1) } & (2) & (3) & (4) & (5) & (6) & (7) & (8) & (9) & (10) \\
\hline & \multicolumn{3}{|c|}{ Goodness of Model Fit } & \multicolumn{3}{|c|}{ Conditional Mean } & \multicolumn{3}{|c|}{ Conditional Variance } \\
\hline & $q_{1}, q_{2}$ & $\bar{R}^{2}$ & $\mathrm{QLR}_{\mathrm{T}}{ }_{\mathrm{T}}$ & SupF & Break & $\Delta \mu$ & SupF & Break & $\Delta \sigma$ \\
\hline AR1 Model & $\overline{1,0}$ & 0.08 & -- & $\begin{array}{l}29.9 \\
(0.00)\end{array}$ & 1974:1 & -- & $\begin{array}{c}28.0 \\
(0.00)\end{array}$ & $991: 1$ & -57.1 \\
\hline \multicolumn{10}{|l|}{ ARDL Models } \\
\hline$\Delta$ Real bank rate & 1,2 & 0.09 & $19.4^{*}$ & $\begin{array}{l}30.1 \\
(0.01)\end{array}$ & $1980: 3$ & -41.2 & $\begin{array}{l}25.2 \\
(0.00)\end{array}$ & 1991:1 & -57.4 \\
\hline$\Delta$ Real Tbill3 rate & 1,2 & 0.09 & $18.6^{*}$ & $\begin{array}{l}29.5 \\
(0.01)\end{array}$ & $1980: 3$ & -41.1 & $\begin{array}{c}27.8 \\
(0.00)\end{array}$ & 1987:1 & -45.8 \\
\hline$\Delta$ Real CP3 rate & 1,2 & 0.11 & $20.4^{*}$ & $\begin{array}{l}30.3 \\
(0.00)\end{array}$ & $1974: 2$ & -40.0 & $\begin{array}{l}29.2 \\
(0.00)\end{array}$ & 1987:1 & -51.1 \\
\hline$\Delta$ Real 1-3Yr Bond Yld & 1,2 & 0.10 & $18.5^{*}$ & $\begin{array}{l}28.9 \\
(0.00)\end{array}$ & $1974: 2$ & -44.0 & $\begin{array}{l}30.1 \\
(0.00)\end{array}$ & 1991:1 & -50.4 \\
\hline$\Delta$ Real 3-5Yr Bond Yld & 1,2 & 0.11 & $17.3^{*}$ & $\begin{array}{l}29.6 \\
(0.00)\end{array}$ & $1974: 2$ & -44.1 & $\begin{array}{l}28.9 \\
(0.00)\end{array}$ & 1991:1 & -48.9 \\
\hline$\Delta$ Real $10^{+}$Yr Bond Yld & 1,2 & 0.12 & $25.8^{*}$ & $\begin{array}{l}31.0 \\
(0.00)\end{array}$ & $1977: 2$ & -41.2 & $\begin{array}{l}24.3 \\
(0.00)\end{array}$ & 1991:1 & -24.7 \\
\hline 1-3 Yr Term Spread & 1,2 & 0.17 & $246.9^{*}$ & $\begin{array}{l}21.7 \\
(0.12)\end{array}$ & $1982: 3$ & -40.0 & $\begin{array}{l}29.9 \\
(0.00)\end{array}$ & $1987: 1$ & -46.1 \\
\hline 3-5 Yr Term Spread & 1,2 & 0.17 & $300.1 *$ & $\begin{array}{l}21.8 \\
(0.09)\end{array}$ & 1981:1 & -42.8 & $\begin{array}{l}28.4 \\
(0.00)\end{array}$ & 1987:1 & -46.3 \\
\hline 5-10 Yr Term Spread & 1,2 & 0.18 & $332.2 *$ & $\begin{array}{l}23.1 \\
(0.08)\end{array}$ & $1981: 3$ & -45.9 & $\begin{array}{l}29.5 \\
(0.00)\end{array}$ & 1987:1 & -48.3 \\
\hline $10-\mathrm{Yr}^{+}$Term Spread & 1,2 & 0.18 & $338.8 *$ & $\begin{array}{l}23.5 \\
(0.06)\end{array}$ & $1982: 3$ & -40.0 & $\begin{array}{l}26.2 \\
(0.00)\end{array}$ & 1987:1 & -46.4 \\
\hline Default Spread & 1,1 & 0.09 & $143^{*}$ & $\begin{array}{c}36.0 \\
(0.00)\end{array}$ & $1972: 4$ & -48.4 & $\begin{array}{c}28.3 \\
(0.00)\end{array}$ & 1991:1 & -49.3 \\
\hline$\Delta$ Real Exchange rate & 1,1 & 0.09 & 11.6 & $\begin{array}{l}27.0 \\
(0.00)\end{array}$ & $1974: 2$ & -44.1 & $\begin{array}{l}31.1 \\
(0.00)\end{array}$ & 1988:1 & -44.8 \\
\hline Growth Real M1 Money & 1,2 & 0.13 & $176.6^{*}$ & $\begin{array}{l}33.6 \\
(0.01)\end{array}$ & 1990:1 & -26.0 & $\begin{array}{l}39.0 \\
(0.00)\end{array}$ & 1989:1 & -40.2 \\
\hline Growth Real TSE300 & 1,1 & 0.13 & $66.5^{*}$ & $\begin{array}{l}27.1 \\
(0.01)\end{array}$ & $1979: 2$ & -25.4 & $\begin{array}{l}9.0 \\
(0.06)\end{array}$ & 1988:2 & -10.6 \\
\hline
\end{tabular}

Cols 2, 3, and 4 report the 'goodness of fit' statistics for the ARDL model (2) associated with the financial variable shown in Col 1; Col 2 shows lag orders chosen by SIC, Col 3 shows $\bar{R}^{2}$. The $Q L R^{*}{ }_{T}$ statistic in $\mathrm{Col}$ (4) tests the null hypothesis that the parameters $\beta_{\mathrm{i}}$ have constant values of zero against the one-sided (upper tail) alternative hypothesis that they have non-zero values for at least part of the sample.*indicates significance at $10 \%$ level or less; critical values are from Rossi (2005). The results of the SupF test, testing model stability against the alternative of a single structural change are reported in cols (5), (6) and (7). The $p$ values generated using Hansen's (2000) fixed regressor bootstrap are in parentheses; the highlighted p-values indicate significance at the $10 \%$ or less. The estimated breakdate and the magnitude of the change in conditional mean growth are in columns (6) and (7) respectively. The SupF test results for a structural change in conditional volatility of growth are reported in columns (8), (9) and (10). 
Table 3: Bai and Perron (1998) statistics for tests for multiple structural breaks in Unconditional and Conditional Mean of Canada's GDP Growth: 1961:2-2004:4

\begin{tabular}{|c|c|c|c|c|c|c|c|c|c|}
\hline \multirow{2}{*}{$\begin{array}{l}\text { (1) } \\
\text { Predictor }\end{array}$} & (2) & \multicolumn{2}{|c|}{ (3) (4) } & $(5)$ & $(6)$ & (7) & $(8)$ & (9) & $(10)$ \\
\hline & $\begin{array}{l}\text { UD } \\
\max ^{a}\end{array}$ & $\begin{array}{l}\text { WD } S u \\
\max ^{\mathrm{a}}\end{array}$ & $\begin{array}{l}o F_{T} \text { Sup } \\
0 \mid 1)^{\mathrm{b}}\end{array}$ & $\begin{array}{l}F_{T} S \\
2 \mid 1)^{\mathrm{c}}\end{array}$ & $\begin{array}{l}u p F_{T} \\
(3 \mid 2)^{\mathrm{d}}\end{array}$ & $\begin{array}{l}\operatorname{SupF}_{T} \\
\quad(4 \mid 3)^{\mathrm{e}}\end{array}$ & $\begin{array}{l}\operatorname{Sup}_{T} \\
\quad(5 \mid 4)^{\mathrm{f}}\end{array}$ & $\begin{array}{l}\text { Break } \\
\text { dates }\end{array}$ & $\begin{array}{l}90 \% \\
\text { CI }\end{array}$ \\
\hline$\underline{\text { Unconditional Mean }}$ & $13.7^{*}$ & $13.7 *$ & $13.7^{*}$ & 3.9 & 7.4 & 3.8 & - & 1974:1 & $69: 2-79: 1$ \\
\hline \multicolumn{10}{|l|}{$\underline{\text { Conditional Mean }}$} \\
\hline$\underline{\text { AR1 Model }}$ & $18.8^{*}$ & $18.6^{*}$ & $18.6^{*}$ & 3.6 & 1.5 & 4.0 & - & 1974:1 & $73: 1-79: 1$ \\
\hline \multicolumn{10}{|l|}{$\underline{\text { ARDL Models }}$} \\
\hline$\Delta$ Real bank rate & $25.8^{*}$ & $25.8^{*}$ & $25.8^{*}$ & 5.6 & 6.2 & 7.6 & 7.6 & 1980:3 & $78: 2-85: 1$ \\
\hline$\Delta$ Real Tbill3 rate & $25.4^{*}$ & $25.4^{*}$ & $25.4 *$ & 5.9 & 7.3 & 8.4 & 8.6 & 1980:3 & $78: 2-85: 1$ \\
\hline$\Delta$ Real $3 \mathrm{~m} \mathrm{CP}$ rate & $21.0^{*}$ & $21.0^{*}$ & $21.0 *$ & 6.8 & 5.7 & 8.7 & 1.3 & $1974: 2$ & $73: 1-77: 2$ \\
\hline$\Delta$ Real 1-3Yr bond yld & $20.0^{*}$ & $20.0^{*}$ & $20.0 *$ & 7.5 & 9.8 & 11.3 & 1.6 & 1974:2 & $71: 3-79: 1$ \\
\hline$\Delta$ Real 3-5Yr bond yld & $20.7^{*}$ & $20.7^{*}$ & $20.7 *$ & 8.2 & 4.8 & 11.0 & 11.0 & $1974: 2$ & $71: 3-78: 4$ \\
\hline$\Delta$ Real $10^{+}$Yr bond yld & $24.8^{*}$ & $24.8^{*}$ & $24.8^{*}$ & 5.6 & 3.8 & 11.5 & 2.1 & $1982: 3$ & $81: 1-86: 3$ \\
\hline 1-3 Yr term spread & $19.1^{*}$ & $20.1 *$ & $19.1 *$ & 9.2 & 4.5 & 7.5 & 6.2 & $1982: 3$ & $80: 3-86: 3$ \\
\hline 3-5 Yr term spread & $19.4^{*}$ & $23.2 *$ & $19.4^{*}$ & 10.2 & 4.6 & 11.2 & 9.5 & 1981:1 & $79: 1-87: 2$ \\
\hline 5-10 Yr term spread & $20.9 *$ & $23.9^{*}$ & $20.9^{*}$ & 8.6 & 5.2 & 12.3 & & $1981: 3$ & $79: 3-87: 2$ \\
\hline $10-\mathrm{Yr}^{+}$term spread & 9.3 & 13.3 & 9.3 & 7.4 & 8.2 & 8.3 & & $1982: 3$ & $75: 1-89: 1$ \\
\hline Default spread & $19.2 *$ & $19.2 *$ & $19.2^{*}$ & 10.6 & 4.9 & 4.9 & $\overline{1.2}$ & $1972: 4$ & $71: 4-76: 4$ \\
\hline$\Delta$ Real Exchange rate & 9.4 & $13.3^{*}$ & 9.4 & 7.4 & 8.3 & 8.3 & - & 1974:2 & $66: 2-78: 2$ \\
\hline Growth Real M1 mo & $37.7 *$ & $37.7 *$ & $37.7 *$ & 10.7 & 6.8 & 12.2 & & 1990:1 & $89: 2-94: 2$ \\
\hline Growth Real TSE300 & 8.1 & $12.3^{*}$ & 7.4 & 12.6 & 2.7 & 7.7 & $\overline{6.7}$ & 1979:2 & $72: 1-88: 2$ \\
\hline
\end{tabular}

*indicates significance at the $10 \%$ level or less, according to critical values in BP(2003); _ indicates that there was no more place to insert an additional break given the minimal length requirement of $15 \%$ of the full sample. a.One-sided (upper tail) test of the null hypothesis of 0 breaks against the alternative hypothesis of an unknown number of breaks given an upper bound of 5 breaks. b. One-sided (upper tail) test of the null hypothesis of 0 breaks against the alternative hypothesis of 1 breaks c.One-sided (upper tail) test of the null hypothesis of 1 break against the alternative hypothesis of 2 breaks d.One-sided (upper tail) test of the null hypothesis of 2 breaks against the alternative hypothesis of 3 break e.One-sided (upper tail) test of the null hypothesis of 3 breaks against the alternative hypothesis of 4 breaks f.One-sided (upper tail) test of the null hypothesis of 4 breaks against the alternative hypothesis of 5 breaks. 
Table 4: BP (1998) tests of multiple structural breaks in unconditional volatility (UV) and conditional volatility (CV) of Canada's real GDP growth, 1961:2-2004:4.

\begin{tabular}{|c|c|c|c|c|c|c|c|c|c|}
\hline$(1)$ & (2) & (3) & (4) & (5) & (6) & (7) & (8) & (9) & $(10)$ \\
\hline Predictor & $\begin{array}{l}\text { UD } \\
\max ^{a}\end{array}$ & $\begin{array}{l}\text { WD } S t \\
\max ^{\mathrm{a}}\end{array}$ & $\begin{array}{l}\operatorname{SupF}_{T} \\
(0 \mid 1)^{\mathrm{b}}\end{array}$ & $\begin{array}{c}\operatorname{SupF}_{T} \\
(2 \mid 1)^{\mathrm{c}}\end{array}$ & $\begin{array}{l}\operatorname{SupF}_{T} \\
(3 \mid 2)^{\mathrm{d}}\end{array}$ & $\begin{array}{l}\operatorname{SupF}_{T} \\
(4 \mid 3)^{\mathrm{e}}\end{array}$ & $\begin{array}{r}\text { Sup } \\
(5 \mid\end{array}$ & $\begin{array}{cc}F_{T} & \text { Break } \\
4)^{\mathrm{f}} & \text { dates }\end{array}$ & $\begin{array}{c}90 \% \\
\mathrm{CI}\end{array}$ \\
\hline \multicolumn{10}{|c|}{ Unconditional volatility (UV) } \\
\hline UV & $32.4^{*}$ & $32.4^{*}$ & $32.4^{*}$ & 2.9 & $16.0^{*}$ & - & - & $\begin{array}{l}1973: 2 \\
1979: 2 \\
1992: 2\end{array}$ & $\begin{array}{c}72: 2-77: 2 \\
76: 1-81: 2 \\
91: 2-95: 2\end{array}$ \\
\hline UV-M & $31.5^{*}$ & $31.5^{*}$ & $31.5^{*}$ & 3.5 & $13.4 *$ & - & - & $\begin{array}{c}1974: 1 \\
1980: 1 \\
1991: 2\end{array}$ & $\begin{array}{c}72: 2-78.2 \\
77.1-81: 4 \\
90.2-94.4\end{array}$ \\
\hline $\begin{array}{l}\text { Conditional Volatility } \\
\text { AR1 Model }\end{array}$ & $47.2 *$ & $47.2^{*}$ & $47.2^{*}$ & 5.2 & $11.2^{*}$ & - & - & $\begin{array}{c}1973: 1 \\
1980: 1 \\
1991: 1\end{array}$ & $\begin{array}{c}72: 2-77: 3 \\
76: 1-83: 1 \\
89: 3-93: 3\end{array}$ \\
\hline \multicolumn{10}{|l|}{$\underline{\text { ARDL Models }}$} \\
\hline$\Delta$ Real bank rate & $43.8^{*}$ & $43.8^{*}$ & $43.8^{*}$ & 6.2 & $9.9^{*}$ & - & - & $\begin{array}{l}1973: 4 \\
1980: 4 \\
1991: 1\end{array}$ & $\begin{array}{l}71: 1-79: 4 \\
75: 4-82: 3 \\
89: 2-94: 1\end{array}$ \\
\hline$\Delta$ Real tbill rate & $43.4^{*}$ & $43.4^{*}$ & $43.4^{*}$ & 5.9 & $10.3^{*}$ & - & - & $\begin{array}{l}1973: 4 \\
1980: 4 \\
1991: 1\end{array}$ & $\begin{array}{l}71: 1-79: 4 \\
75: 4-82: 3 \\
89: 2-94: 1\end{array}$ \\
\hline$\Delta$ Real 1-3Yr bond yld & $40.7 *$ & $40.7^{*}$ & $40.7^{*}$ & 6.1 & $10.4^{*}$ & - & - & $\begin{array}{l}1973: 4 \\
1980: 1 \\
1990: 4\end{array}$ & $\begin{array}{l}71: 1-79: 4 \\
75: 1-84: 2 \\
90: 1-94: 2\end{array}$ \\
\hline$\Delta$ Real $10^{+}$Yr bond yld & $17.5^{*}$ & $17.5^{*}$ & * $17.5^{*}$ & $12.7^{*}$ & $10.2^{*}$ & - & - & $\begin{array}{l}\text { 1973:4 } \\
\text { 1980:2 } \\
1991: 1\end{array}$ & $\begin{array}{l}71: 1-79: 4 \\
74: 4-84: 2 \\
89: 4-94: 2\end{array}$ \\
\hline 1-3Yr term spread & $19.1^{*}$ & $19.1 *$ & $19.1^{*}$ & $9.0^{*}$ & 8.9 & - & - & $\begin{array}{l}1973: 4 \\
1987: 1\end{array}$ & $\begin{array}{l}72: 2-79: 1 \\
82: 4-95: 4\end{array}$ \\
\hline $10 \mathrm{Yr}^{+}$term spread & $19.8^{*}$ & $19.8^{*}$ & * $19.8^{*}$ & 4.8 & $10.6^{*}$ & - & - & $\begin{array}{l}1973: 4 \\
1980: 1 \\
1987: 1\end{array}$ & $\begin{array}{c}72: 2-79: 1 \\
77: 2-81: 4 \\
82: 4-95: 4\end{array}$ \\
\hline Growth Real M1 & $44.6^{*}$ & $44.6^{*}$ & $44.6^{*}$ & 7.6 & $15.2 *$ & - & - & $\begin{array}{l}1974: 1 \\
1980: 1 \\
1091 \cdot 1\end{array}$ & $\begin{array}{l}73: 2-77: 1 \\
76: 2-82: 2\end{array}$ \\
\hline Growth Real TSE300 & $43.5^{*}$ & $43.5^{*}$ & $43.5^{*}$ & 6.7 & $9.8^{*}$ & - & - & $\begin{array}{l}1991: 1 \\
1973: 2 \\
1980: 2 \\
1991: 2\end{array}$ & $\begin{array}{l}89: 1-96: 2 \\
72: 1-78: 4 \\
76: 2-82: 4 \\
89: 2-93: 4\end{array}$ \\
\hline
\end{tabular}

\footnotetext{
* indicates significance at the $10 \%$ level or less; critical values from BP(2003); minimal length of a regime is $15 \%$ of the full sample; _ indicates that there was no more place to insert an additional break given the minimal length requirement. aTest of the null hypothesis of 0 breaks against the alternative of an unknown number of breaks, given an upper bound of 5 breaks.bTest of the null hypothesis of 0 breaks against the alternative hypothesis of 1 breaks cTest of the null hypothesis of 1 break against the alternative hypothesis of 2 breaks dTest of the null hypothesis of 2 breaks against the alternative hypothesis of 3 break eTest of the null hypothesis of 3 breaks against the alternative hypothesis of 4 breaks f.Test of the null hypothesis of 4 breaks against the alternative hypothesis of 5 breaks.
} 
Table 5: BP (1998) tests for Multiple Structural Changes in unconditional volatility (UV) and conditional volatility $(\mathrm{CV})$ after allowing for Business Cycle Asymmetry

\begin{tabular}{|c|c|c|c|c|c|c|c|c|c|}
\hline (1) & (2) & (3) & (4) & (5) & (6) & (7) & (8) & (9) & (10) \\
\hline Predictor & $\begin{array}{l}\text { UD } \\
\max ^{a}\end{array}$ & $\begin{array}{l}\text { WD } \\
\max ^{a}\end{array}$ & $\begin{array}{c}\operatorname{SupF}_{T} \\
(0 \mid 1)^{\mathrm{b}}\end{array}$ & $\begin{array}{l}\operatorname{Sup}_{T} \\
(2 \mid 1)^{\mathrm{c}}\end{array}$ & $\begin{array}{l}\operatorname{SupF}_{T} \\
\quad(3 \mid 2)^{\mathrm{e}}\end{array}$ & $\begin{array}{l}\operatorname{SupF}_{T} \\
(4 \mid 3)^{\mathrm{e}}\end{array}$ & $\begin{array}{r}S u p F_{T} \\
(5 \mid 4)\end{array}$ & $\begin{array}{r}\text { Break } \\
\text { f dates }\end{array}$ & $\begin{array}{c}90 \% \\
\mathrm{CI}\end{array}$ \\
\hline$\underline{\text { Unconditional Volatility }}$ & $16.8^{*}$ & $16.8^{*}$ & $16.8^{*}$ & 7.1 & 2.8 & - & - & 1973:2 & $71: 4-78: 3$ \\
\hline$\frac{\text { Conditional Volatility }}{\text { AR1 Model }}$ & $17.8^{*}$ & $17.8^{*}$ & $17.8^{*}$ & 6.4 & 1.9 & - & - & 1973:4 & $72: 2-78: 1$ \\
\hline$\underline{\text { ARDL Models }}$ & & & & & & & & & \\
\hline$\Delta$ Real bank rate & $17.5^{*}$ & $17.5^{*}$ & $17.5^{*}$ & 5.5 & 2.6 & - & - & 1973:1 & $71: 1-80: 1$ \\
\hline$\Delta$ Real tbill rate & $16.8^{*}$ & $16.8^{*}$ & $16.8^{*}$ & 5.4 & 2.3 & - & -1 & 1973:4 & $72: 2-78: 1$ \\
\hline$\Delta$ Real CP rate & $16.1^{*}$ & $16.1^{*}$ & $16.1^{*}$ & 6.4 & 2.0 & - & -1 & 1973:1 & $71: 1-78: 3$ \\
\hline$\Delta 1-31$ Yr Real bond yld & $17.3^{*}$ & $17.3^{*}$ & $17.3^{*}$ & 5.3 & 1.5 & - & - & 1973:1 & $71: 1-78: 1$ \\
\hline$\Delta$ 3-5Yr Real bond yld & $17.1^{*}$ & $17.1^{*}$ & $17.1 *$ & 5.3 & 1.6 & - & - & 1973:4 & $72: 2-78: 1$ \\
\hline $\begin{array}{l}\Delta 10^{+} \text {Yr Real bond yld } \\
1-3 \mathrm{Yr} \text { term spread }\end{array}$ & $\begin{array}{c}17.5^{*} \\
195^{*}\end{array}$ & $\begin{array}{l}17.5^{*} \\
19.5^{*}\end{array}$ & $\begin{array}{c}17.5^{*} \\
19.5^{*}\end{array}$ & $\begin{array}{c}3.9 \\
3.6\end{array}$ & $\begin{array}{l}2.2 \\
1.6\end{array}$ & - & - & $\begin{array}{l}1973: 4 \\
1973 \cdot 4\end{array}$ & $\begin{array}{l}72: 2-78: 1 \\
72 \cdot 2-79: 1\end{array}$ \\
\hline 3-5Yr term spread & $19.1^{*}$ & $19.1 *$ & $19.1 *$ & $\begin{array}{l}3.0 \\
2.1\end{array}$ & 3.7 & - & - & $1973: 4$ & $72: 2-79: 1$ \\
\hline $5-10$ Yr term spread & $19.0^{*}$ & $19.0^{*}$ & $19.0^{*}$ & 2.2 & 3.6 & & - & 1973:4 & $72: 2-79: 1$ \\
\hline $10 \mathrm{Yr}^{+}$term spread & $19.1^{*}$ & $19.1 *$ & $19.1 *$ & 2.7 & 3.0 & - & - & 1973:4 & $72: 2-79: 1$ \\
\hline Default spread & $16.9^{*}$ & $16.9 *$ & $16.9 *$ & 5.6 & 1.3 & & - & 1973:4 & $72: 1-78: 4$ \\
\hline$\Delta$ Real Exchange rate & $17.4^{*}$ & $17.4^{*}$ & $17.4^{*}$ & 7.0 & 1.9 & & & 1973:4 & $72: 2-78: 1$ \\
\hline Growth Real M1 & $16.3^{*}$ & $16.3^{*}$ & $16.3^{*}$ & 4.6 & 4.1 & & & 1973:4 & $72: 2-78: 1$ \\
\hline Growth Real TSE300 & $19.2^{*}$ & $19.2 *$ & $19.2^{*}$ & 6.3 & 2.0 & - & - & 1973:4 & $72: 2-77: 1$ \\
\hline
\end{tabular}

*indicates significance at 5\% level or less, according to critical values in BP(2003); the minimal length of any regime is required to be $15 \%$ of the full sample; _ indicates that there was no more place to insert an additional break given the minimal length requirement.

aOne-sided (upper tail) test of the null hypothesis of 0 breaks against the alternative hypothesis of an unknown number of breaks, given an upper bound of 5 breaks.

bOne-sided (upper tail) test of the null hypothesis of 0 breaks against the alternative hypothesis of 1 breaks cOne-sided (upper tail) test of the null hypothesis of 1 break against the alternative hypothesis of 2 breaks dOne-sided (upper tail) test of the null hypothesis of 2 breaks against the alternative hypothesis of 3 break eOne-sided (upper tail) test of the null hypothesis of 3 breaks against the alternative hypothesis of 4 breaks fOne-sided (upper tail) test of the null hypothesis of 4 breaks against the alternative hypothesis of 5 breaks. 


\begin{tabular}{|c|c|c|c|c|c|c|c|c|}
\hline Horizon (h): & \multicolumn{2}{|c|}{1 Quarter Ahead } & \multicolumn{2}{|c|}{2 Quarters Ahead } & \multicolumn{2}{|c|}{4 Quarters Ahead } & \multicolumn{2}{|c|}{8 Quarters Ahead } \\
\hline $\begin{array}{l}\text { Out-of-Sample } \\
\text { Period }\end{array}$ & $1973: 4-1984: 4$ & $1985: 1-2004: 4$ & $1973: 4-1984: 4$ & $1985: 1-2004: 4$ & $1973: 4-1984: 4$ & $1985: 1-2004: 4$ & $1973: 4-1984: 4$ & 1985:1-2004 \\
\hline
\end{tabular}

\section{$\triangle$ Real Bank rate}

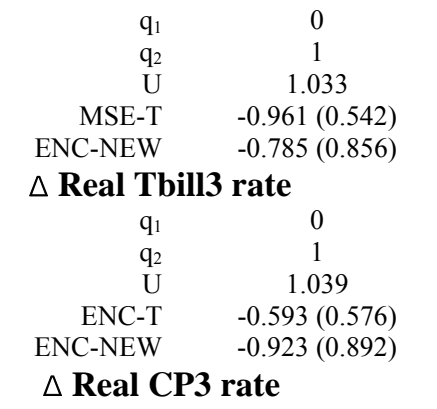

$\begin{array}{rc}\mathrm{q}_{1} & 0 \\ \mathrm{q}_{2} & 1 \\ \mathrm{U} & 1.045 \\ \text { MSE-T } & -1.236(0.712) \\ \text { ENC-NEW } & -1.064(0.926)\end{array}$

$\triangle$ Real 1-3Yr Bond Yield

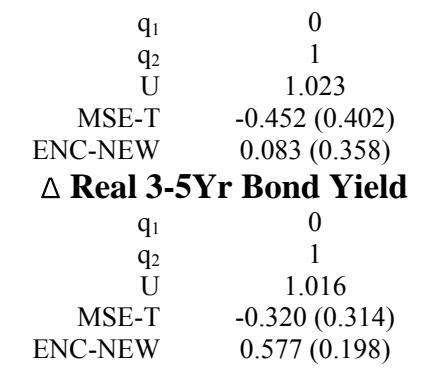

\section{$\triangle$ Real 10Yr ${ }^{+}$Bond Yield}

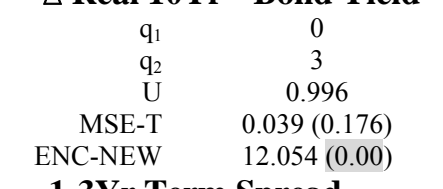

\section{1-3Yr Term Spread}

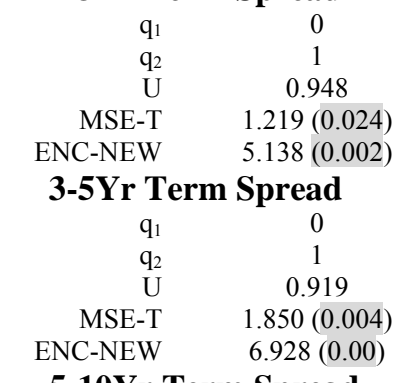

\section{5-10Yr Term Spread}

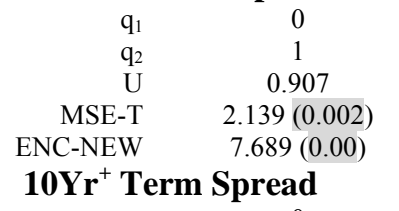

\section{$10 \mathrm{Yr}^{+}$Term Spread}

$\begin{array}{rc}\mathrm{q}_{2} & 1 \\ \mathrm{U} & 0.909 \\ \text { MSE-T } & 2.341(0.00) \\ \text { ENC-NEW } & 6.842(0.002)\end{array}$

\section{Default Spread}

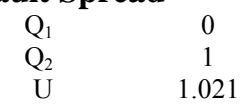

$\begin{array}{ccc}1 & 0 & 0 \\ 1 & 1 & 5 \\ 0.999 & 1.022 & 1.078 \\ 0.078(0.236) & -0.512(0.392) & -0.745(0.572) \\ 0.433(0.234) & -0.256(0.582) & 2.154(0.056)\end{array}$

0
2
0.948
$0.694(0.076)$
$6.950(0.006)$

$\begin{array}{cc}0 & 0 \\ 5 & 1 \\ 1.096 & 0.977 \\ -0.733(0.532) & 1.155(0.066) \\ 1.191(0.116) & 1.442(0.096)\end{array}$

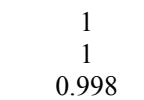

$0.927(0.164)$

$0.568(0.232)$
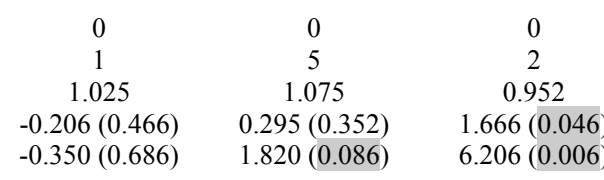

$6.206(0.006)$
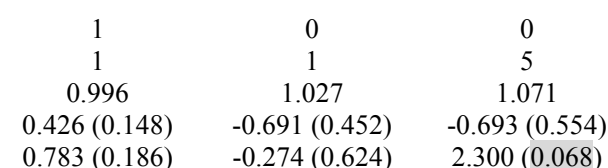
0
2
0.941
$0.829(0.072)$

$0.783(0.186)$

$-0.274(0.624)$
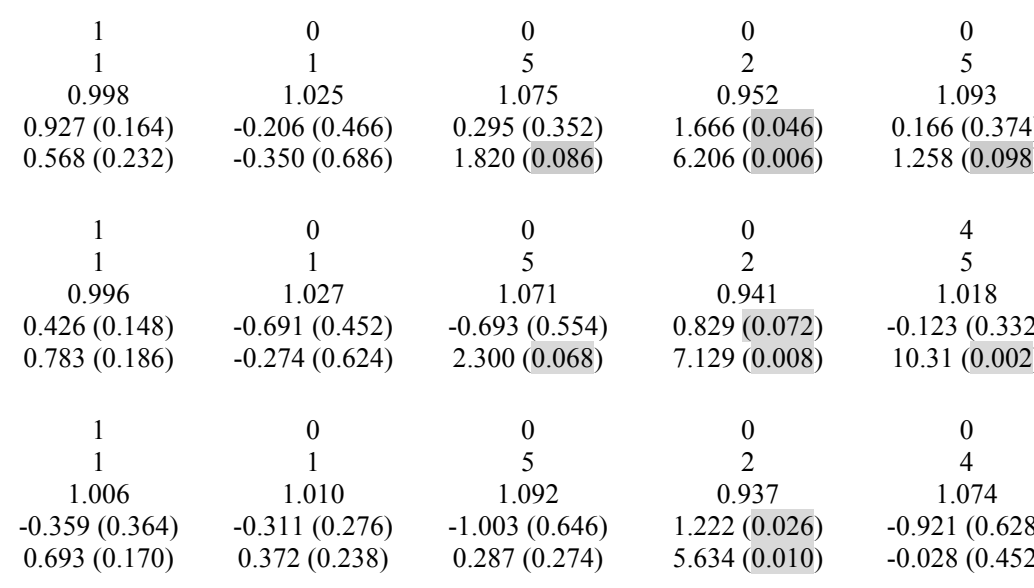

$1.258(0.098)$

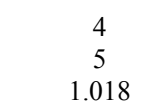

$-0.123(0.332)$

$10.31(0.002)$
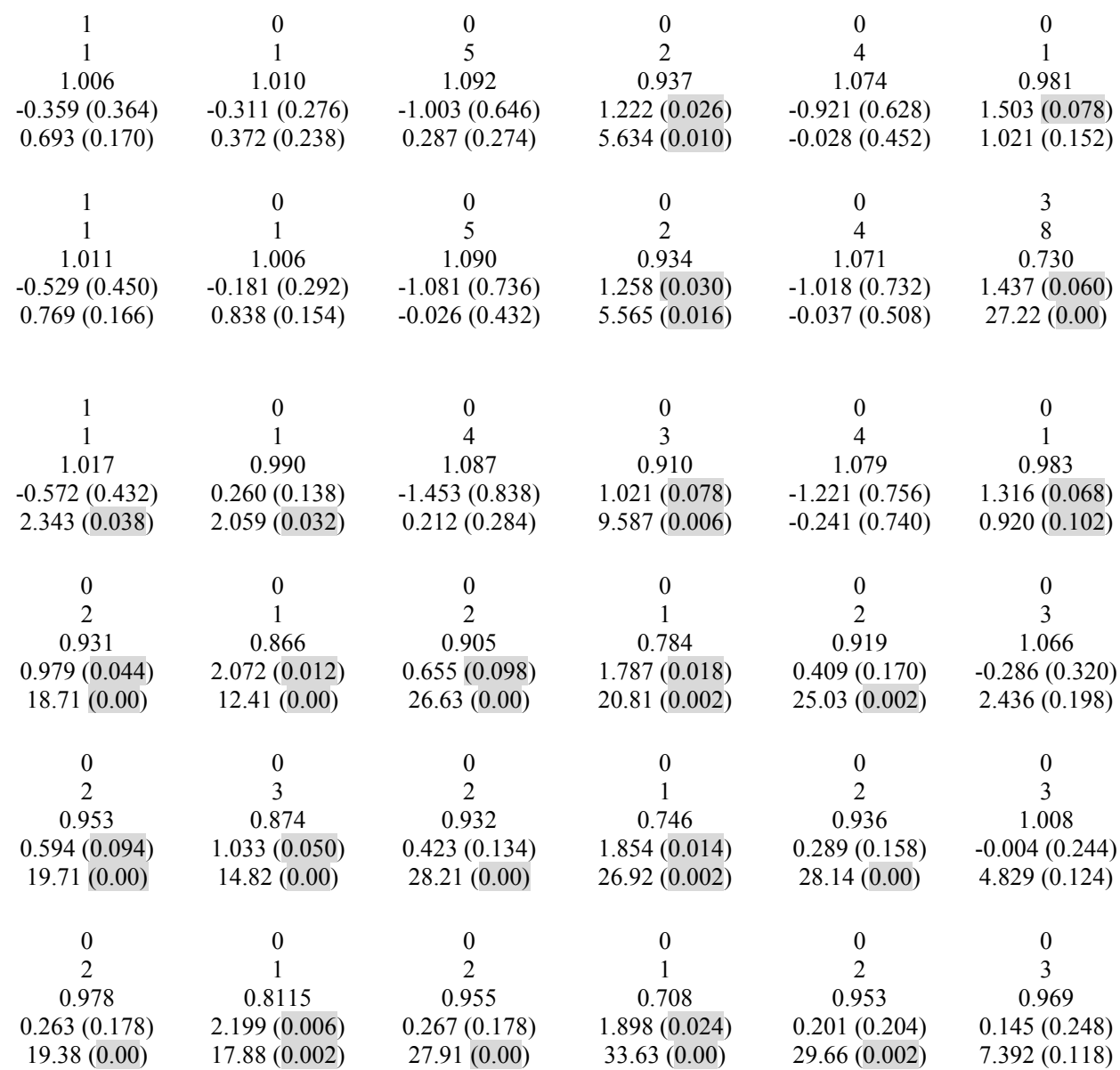

$29.66(0.002)$ $\begin{array}{lll}1.15(0.00) & 27.98(0.00) & 2.515(0.244)\end{array}$
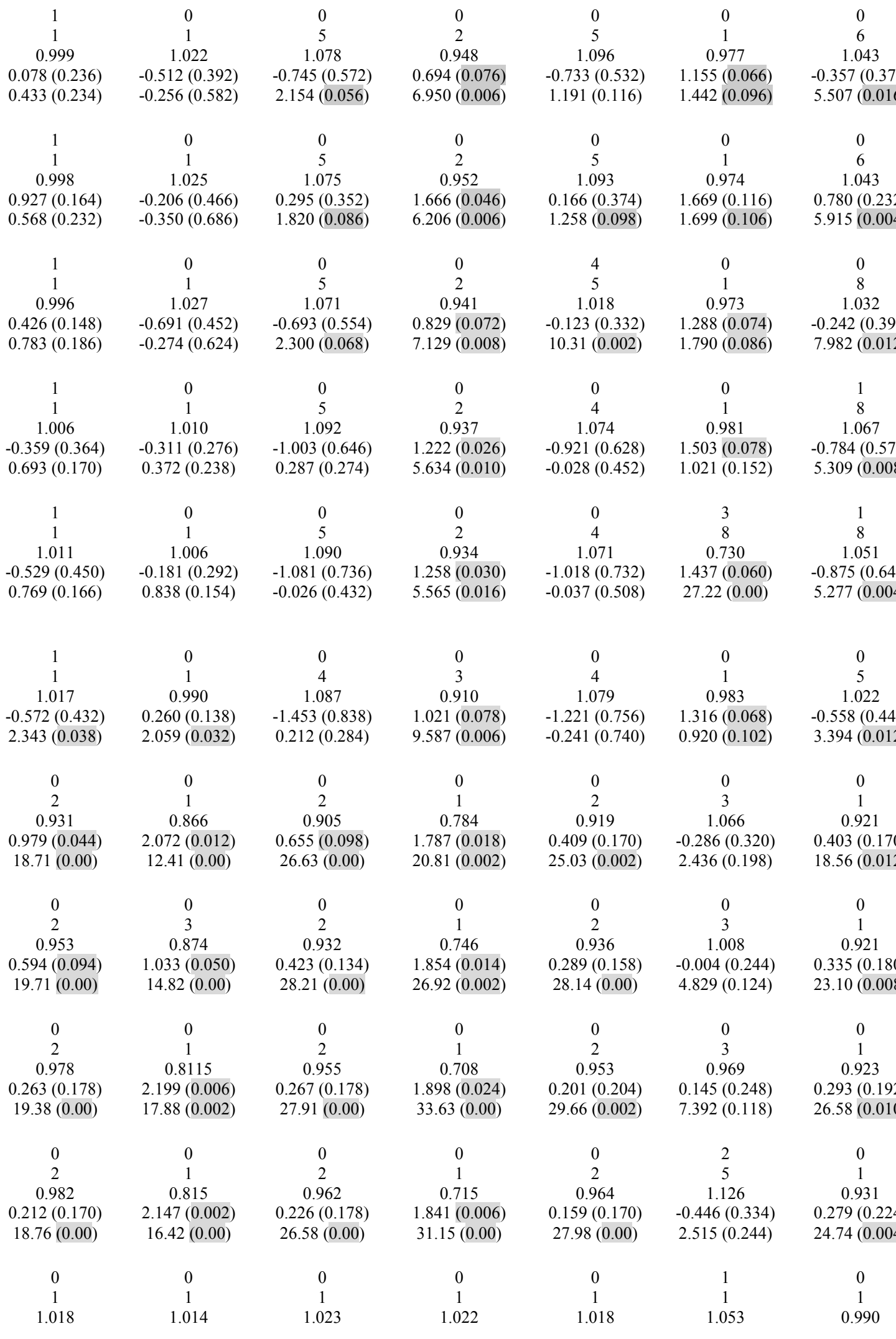


\begin{tabular}{|c|c|c|c|c|c|c|c|c|}
\hline MSE-T & $-0.633(0.450)$ & $-2.333(0.972)$ & $-0.353(0.288)$ & $-2.046(0.928)$ & $-0.449(0.302)$ & $-1.528(0.790)$ & $-0.735(0.392)$ & $1.001(0.09$ \\
\hline ENC-NEW & $0.876(0.114)$ & $1.252(0.958)$ & $1.242(0.192)$ & $-1.615(0.904)$ & $0.154(0.384)$ & $-1.276(0.694)$ & $0.198(0.414)$ & $0.975(0.32$ \\
\hline \multicolumn{9}{|c|}{ Real M1 Money Growth } \\
\hline $\mathrm{q}_{1}$ & 0 & 0 & 0 & 0 & 0 & 2 & 0 & 1 \\
\hline $\mathrm{q}_{2}$ & 1 & 1 & 1 & 1 & 1 & 2 & 1 & 1 \\
\hline $\mathrm{U}$ & 0.770 & 1.095 & 0.729 & 1.107 & 0.661 & 1.279 & 0.738 & 1.172 \\
\hline MSE-T & $3.128(0.00)$ & $-1.947(0.944)$ & $1.918(0.010)$ & $-1.406(0.778)$ & $1.971(0.016)$ & $-3.706(1.00)$ & $2.204(0.022)$ & $-2.559(0.97$ \\
\hline ENC-NEW & $22.25(0.00)$ & $3.800(0.026)$ & $30.09(0.00)$ & $5.606(0.010)$ & $47.19(0.00)$ & $-1.561(0.798)$ & $25.28(0.006)$ & $-0.956(0.54$ \\
\hline \multicolumn{9}{|c|}{$\Delta$ Real Exchange Rate } \\
\hline $\mathrm{q}_{1}$ & 0 & 0 & 0 & 0 & 0 & 0 & 0 & 0 \\
\hline$q_{2}$ & 1 & 1 & 1 & 1 & 1 & 1 & 1 & 1 \\
\hline $\mathrm{U}$ & 1.007 & 1.007 & 1.011 & 1.005 & 1.018 & 1.002 & 1.012 & 1.012 \\
\hline MSE-T & $-1.641(0.854)$ & $-0.945(0.568)$ & $-0.108(0.636)$ & $-1.946(0.904)$ & $-1.881(0.884)$ & $-0.669(0.484)$ & $-0.894(0.496)$ & $-1.135(0.68$ \\
\hline ENC-NEW & $-0.296(0.610)$ & $-0.315(0.674)$ & $-0.306(0.592)$ & $-0.395(0.636)$ & $-0.543(0.672)$ & $-0.113(0.452)$ & $-0.288(0.558)$ & $-0.757(0.75$ \\
\hline \multicolumn{9}{|c|}{ Growth in Real TSE300 } \\
\hline $\mathrm{q}_{1}$ & 0 & 0 & 0 & 0 & 0 & 0 & 0 & 0 \\
\hline $\mathrm{q}_{2}$ & 1 & 1 & 1 & 1 & 1 & 1 & 1 & 1 \\
\hline $\mathrm{U}$ & 0.906 & 1.000 & 0.895 & 0.993 & 0.929 & 1.006 & 1.017 & 0.993 \\
\hline MSE-T & $2.052(0.004)$ & $-0.003(0.284)$ & $1.183(0.054)$ & $0.135(0.220)$ & $0.969(0.088)$ & $-0.141(0.264)$ & $-0.536(0.366)$ & $0.704(0.13$ \\
\hline ENC-NEW & $7.496(0.002)$ & $4.737(0.014)$ & $9.527(0.012)$ & $7.170(0.006)$ & $6.351(0.026)$ & $3.884(0.042)$ & $-0.399(0.568)$ & $0.999(0.17$ \\
\hline
\end{tabular}

Notes: $q_{1}$ and $q_{2}$ are lag orders chosen by SIC for unrestricted equation 1 . TU =RMSFE ${ }_{1} / R M S F E_{0}$ where RMSFE and $M S E F E_{0}$ are the unrestricted and restricted model out-of-sample root mean square forecast errors respectively; the $M S E-F$ statistic tests the null hypothesis that RMSFE $E_{1}=R M S F E_{0}$; the ENC-NEW statistic tests the null hypothesis that the restricted model(Equation 1) encompasses the restricted model (Equation 1 with $\beta_{0}=\ldots=\beta_{q_{2}-1}=0$ ). 
Table 7: Least Square Estimate of Forecast Bias, the Weight $(\lambda)$ Attached to the ARDL Forecast in an Optimal composite Forecast, Canada's Real GDP Growth, 1985:1-2004:4 Out-of-Sample Period.

\begin{tabular}{|c|c|c|c|c|}
\hline Horizon (h) & $\begin{array}{l}1 \text { Quarter } \\
\text { Ahead }\end{array}$ & $\begin{array}{l}2 \text { Quarters } \\
\text { Ahead }\end{array}$ & $\begin{array}{l}4 \text { Quarter } \\
\text { Ahead }\end{array}$ & $\begin{array}{l}8 \text { Quarters } \\
\text { Ahead }\end{array}$ \\
\hline$\underset{\mathrm{b}}{\Delta \text { Real Bank Rate }}$ & & $0.68(0.06)$ & $0.67(0.06)$ & $0.69(0.05)$ \\
\hline$\lambda$ & & 0.34 & 0.32 & 0.68 \\
\hline $\mathrm{U}$ & & 0.93 & 0.91 & 0.84 \\
\hline$\underset{\mathrm{b}}{\Delta}$ Real TBill3 Rate & & $0.68(0.06)$ & $0.68(0.06)$ & $0.69(0.05)$ \\
\hline$\lambda$ & & 0.34 & 0.33 & 0.69 \\
\hline $\mathrm{U}$ & & 0.93 & 0.91 & 0.84 \\
\hline$\Delta$ Real CP3 Rate & & & & \\
\hline B & & $0.68(0.06)$ & $0.74(0.05)$ & $0.69(0.04)$ \\
\hline$\lambda$ & & 0.36 & 0.55 & 0.76 \\
\hline $\mathrm{U}$ & & 0.92 & 0.89 & 0.82 \\
\hline$\underset{\mathrm{b}}{\Delta}$ Real 1-3Yr Bond Yield & & & & $0.68(0.04)$ \\
\hline$\lambda$ & & & & 0.80 \\
\hline $\mathrm{U}$ & & & & 0.82 \\
\hline$\underset{\mathrm{b}}{\Delta}$ Real $10 \mathrm{Yr}^{+}$Bond Yield & $0.80(0.07)$ & & & $0.70(0.05)$ \\
\hline$\lambda$ & 0.39 & & & 1.13 \\
\hline $\mathrm{U}$ & 0.95 & & & 0.82 \\
\hline $\begin{array}{l}\text { 1-3Yr Term Spread } \\
\text { b }\end{array}$ & $0.66(0.05)$ & $0.65(0.05)$ & $0.64(0.04)$ & $0.67(0.04)$ \\
\hline$\lambda$ & 0.94 & 0.91 & 0.84 & 1.05 \\
\hline $\mathrm{U}$ & 0.83 & 0.77 & 0.79 & 0.77 \\
\hline $\begin{array}{l}\text { 3-5Yr Term Spread } \\
\text { b }\end{array}$ & $0.65(0.06)$ & $0.64(0.05)$ & $0.64(0.04)$ & $0.67(0.04)$ \\
\hline$\lambda$ & 0.77 & 0.76 & 0.68 & 0.84 \\
\hline $\mathrm{U}$ & 0.83 & 0.77 & 0.76 & 0.72 \\
\hline $\begin{array}{l}\text { 5-10Yr Term Spread } \\
\text { b }\end{array}$ & $0.65(0.05)$ & $0.64(0.04)$ & $0.64(0.04)$ & $0.67(0.04)$ \\
\hline$\lambda$ & 0.69 & 0.69 & 0.73 & 0.91 \\
\hline $\mathrm{U}$ & 0.84 & 0.77 & 0.77 & 0.74 \\
\hline $\begin{array}{l}10 \mathrm{Yr}^{+} \text {Term Spread } \\
\mathrm{b}\end{array}$ & $0.65(0.05)$ & $0.64(0.04)$ & $0.64(0.04)$ & $0.67(0.04)$ \\
\hline$\lambda$ & 0.67 & 0.68 & 0.67 & 0.83 \\
\hline $\mathrm{U}$ & 0.84 & 0.78 & 0.76 & 0.72 \\
\hline $\begin{array}{l}\text { Real M1 Money Growth } \\
\text { b }\end{array}$ & $0.61(0.05)$ & $0.61(0.05)$ & & \\
\hline$\lambda$ & 0.95 & 1.00 & & \\
\hline U & 0.85 & 0.79 & & \\
\hline $\begin{array}{l}\text { Real TSE300 Growth } \\
\text { b }\end{array}$ & $0.71(0.07)$ & $0.71(0.06)$ & $0.72(0.05)$ & \\
\hline$\lambda$ & 0.66 & 0.71 & 0.65 & \\
\hline $\mathrm{U}$ & 0.92 & 0.88 & 0.89 & \\
\hline
\end{tabular}

Notes: $\lambda$ is the estimated weight attached to the ARDL forecast in an optimal composite forecast using regression model (10), with an intercept term included. $U$ is the ratio of the RMSFE of the optimal combined forecast to the RMSFE of the AR forecast. The estimate of $\mathrm{b}$ is obtained from the regression $Z_{t+h}=b \hat{z}_{1, t+h}$. If $\mathrm{b}$ is less than or equal to $1 / 2$ and greater than 0 , then the forecast is severely biased, which may cause ENC-NEW to be significant even when MSE-F is not significant. 